\title{
iTRAQ-based quantitative proteomics analysis of rice leaves infected by Rice stripe virus reveals several proteins involved in symptom formation
}

Biao Wang ${ }^{1}$, Jamal-U-Ddin Hajano ${ }^{1}$, Yingdang Ren², Chuantao Lu² and Xifeng Wang ${ }^{1 *}$

\begin{abstract}
Background: Rice plants infected by Rice stripe virus (RSV) usually leads to chlorosis and death of newly emerged leaves. However, the mechanism of RSV-induced these symptoms was not clear.

Methods: We used an iTRAQ approach for a quantitative proteomics comparison of non-infected and infected rice leaves. RT-qPCR and Northern blot analyses were performed for assessing the transcription of candidate genes.

Results: As a whole, 681 (65.8\% downregulated, $34.2 \%$ upregulated infected vs. non-infected) differentially accumulated proteins were identified. A bioinformatics analysis indicated that ten of these regulated proteins are involved in chlorophyll biosynthesis and three in cell death processes. Subsequent RT-qPCR results showed that downregulation of magnesium chelatase was due to reduced expression levels of the genes encoding subunits CHLI and CHLD, which resulted in chlorophyll reduction involved in leaf chlorosis. Three aspartic proteases expressed higher in RSV-infected leaves than those in the control leaves, which were also implicated in RSV-induced cell death. Northern blot analyses of CHLI and p0026h03.19 confirmed the RT-qPCR results.

Conclusions: The magnesium chelatase and aspartic proteases may be associated with RSV-induced leaf chlorosis and cell death, respectively. The findings may yield new insights into mechanisms underlying rice stripe disease symptom formation.
\end{abstract}

Keywords: Rice, Proteome, iTRAQ, Magnesium chelatase, Peptidase, Plant defense

\section{Background}

Rice stripe virus (RSV), a member of the genus Tenuivirus, is one of the most economically important viruses in eastern Asia including China, Korea, and Japan [1]. In 1964, RSV was reported for the first time in Zhejiang Province [2] and then spread to 18 provinces in ricegrowing areas of China [3]. From 2000 to 2005, $1,700,000$ ha of rice fields were affected by this virus in Jiangsu Province, including 1,000,000 ha area where incidence was so severe that yield losses exceeded $50 \%$, and in some places no rice was harvested [4].

RSV is transmitted predominantly in a persistent propagative manner by the small brown planthopper (SBPH; Laodelphax striatellus Fallen) [5] and can be

\footnotetext{
* Correspondence: wangxifeng@caas.cn

'State Key Laboratory for Biology of Plant Diseases and Insect Pests, Institute of Plant Protection, Chinese Academy of Agricultural Sciences, 100193, Beijing, China

Full list of author information is available at the end of the article
}

transmitted transovarially for more than 40 generations [6]. RSV has four single-stranded RNA segments, named RNA 1, 2, 3 and 4 in order of their molecular weight. Among these, RNA 3 encodes a nucleocapsid protein (NCP) from the viral complementary RNA [7], while RNA 4 encodes a disease specific protein (SP) from the viral RNA [8]. RSV-induced symptoms of rice typically are chlorotic stripes and mottlings on the leaves. Newly emerged leaves exhibit yellow stripes or necrosis, then folding and twisting; plants are stunted and finally dead [1].

Leaf chlorosis in general is widely accepted as a sign of reduction in chlorophyll $[9,10]$, and leaf chlorosis upon virus infection is also related to decreased chlorophyll [11]. Subsequent studies have shown that various molecular mechanisms are involved in leaf chlorosis during virus infection. For example, during Cucumber mosaic virus (CMV) infection, the expression of the genes 
encoding magnesium chelatase is regulated by CMV satellite RNA, thus blocking chlorophyll biosynthesis [12, 13]. In addition, chlorotic symptoms induced by African cassava mosaic virus (ACMV) are linked to the expression level of chlorophyll-related genes encoding proteins such as chlorophyllide a and chlorophyllide b [14]. However, the chlorosis on tobacco leaves during the flavum strain of Tobacco mosaic virus (TMV) infection not resulted from the reduction of chlorophyll biosynthesis, but was reduction of the core complexes of photosystem II and the oxygen evolving complex [15]. In a recent report, RSV SP interacted with PsbP (an oxygen-evolving complex protein) resulting in the downregulation of PsbP in chloroplasts, and then modulating RSV symptoms through disruption of chloroplast structure and function [16]. Whether other chlorophyll relation proteins are modulated during RSV infection has not been known.

In addition, if the cultivar is susceptible to RSV infection, newly emerged rice leaves usually exhibit necrosis [1]. Previous report indicated that a vacuolar processing enzyme that has caspase protease activity was indispensable for the TMV-induced hypersensitive response, which involves programmed cell death in tobacco [17]. Even in an uninfected healthy plant, the expression of aspartic proteases induces programmed cell death, and then involves in senescence [18]. Nevertheless, we still need to elucidate how the expression of aspartic proteases is regulated after RSV infection. Therefore, the key rice protein(s) involved in RSV-induced disease symptom formation require(s) further exploration.

Some techniques have been shown as powerful tools for understanding plant-pathogen interactions, including yeast two-hybrid system [19-21], glutathione-S transferase pull-down assay [22, 23], immunofluorescence laser scanning confocal microscopy [24, 25], 2D gel-based technology [26, 27], and iTRAQ (isobaric tag for relative and absolute quantitation) LC-MS/MS (liquid chromatography tandem mass spectrometry) technology [28]. iTRAQ LC-MS/MS technology adopted stable isotope labeling strategies of proteins or peptides for measurement and allowed relative quantitation comparison using an internal reference, and could simultaneously label and accurately quantify proteins from multiple samples $[29,30]$. In this study, by using an iTRAQ-based quantitative proteomics approach, we analyzed protein accumulation profiles of RSV-infected leaves in comparison with healthy leaves to explore symptom formation and to understand rice-RSV interactions.

\section{Results}

Symptom formation and RT-PCR confirmation of infection There were 10 viruliferous $\mathrm{SBPH}$ allowed to feed on each plant of cv. Aichiasahi for 2-day inoculation access period. Newly emerged leaves on the initially inoculated plant developed pale-yellow stripes, which then collapsed in the form of blotches at 21 days post inoculation (dpi) (Fig. 1a). At 23 dpi, severe necrosis resulted in plant death (Fig. 1b). No disease symptoms were observed on mock plants. Samples of RSV-infected plants and control plants that were collected at $21 \mathrm{dpi}$ to confirm infection by RT-PCR yielded an expected 969-bp fragment that was also found in a previously confirmedpositive sample (Fig. 1c). The 969-bp fragment was not present in the mock control or no-template control (NTC).

\section{Protein identification and quantification}

When the iTRAQ approach was used to analyze proteins obtained from RSV-infected leaves and mock leaves which were collected at $21 \mathrm{dpi}, 128,144$ spectra were totally obtained from an ABI-5600 system and then approximately 59,824 MS spectra identified matched known spectra. Overall, 3687 different proteins were identified when a false discovery rate (FDR) $<1 \%$ was applied to the dataset (Fig. 2). A total of 681 proteins were differentially accumulated, with a fold-change $>1.5$ $(P<0.05)$; 448 were downregulated, and 223 had a foldchange $<0.67(P<0.05)$ (Table 1$)$.

\section{Bioinformatics analysis}

The identified and quantified proteins were then analyzed for function, pathway and interaction network. In the GO analysis, 358 proteins were involved in molecular function, 233 (70.2 \%, 35 functional groups) were downregulated and 125 (70.2 \%, 16 functional groups) were upregulated (Table 1, Additional file 1: Table S1). The molecular function of downregulated proteins was mainly in cofactor binding (14.2\%), electron carrier activity (10.7\%), coenzyme binding (10.3\%), calcium ion binding (6.0\%), antioxidant activity (5.6\%), magnesium ion binding (4.7\%), peroxidase activity (3.9\%), vitamin B6 binding (3.4\%), FAD (flavin adenine dinucleotide) binding (3.4\%), and primary active transmembrane transporter activity (3.0 \%) (Fig. 3a, Additional file 1: Table S1). Upregulated proteins were involved in cofactor binding (15.2\%), peptidase activity (13.6\%), coenzyme binding (12.0\%), electron carrier activity (12.0\%), endopeptidase activity ( $8.8 \%)$, threonine-type peptidase activity (5.6\%), antioxidant activity (5.6\%), unfolded protein binding (4.8\%), FAD binding (4.8\%), and disulfide oxidoreductase activity (4.0\%) (Fig. 3b, Additional file 1: Table S1). Peptidase activity, the largest group within the catalytic activity group, comprised metallopeptidase activity, aspartic-type endopeptidase, cysteine-type peptidase activity, serine-type peptidase activity. Biological process was influenced by 315 proteins, 203 (61.1 \%, 53 functional groups) downregulated proteins which mostly were involved in oxidation reduction (23.2\%), nitrogen compound 


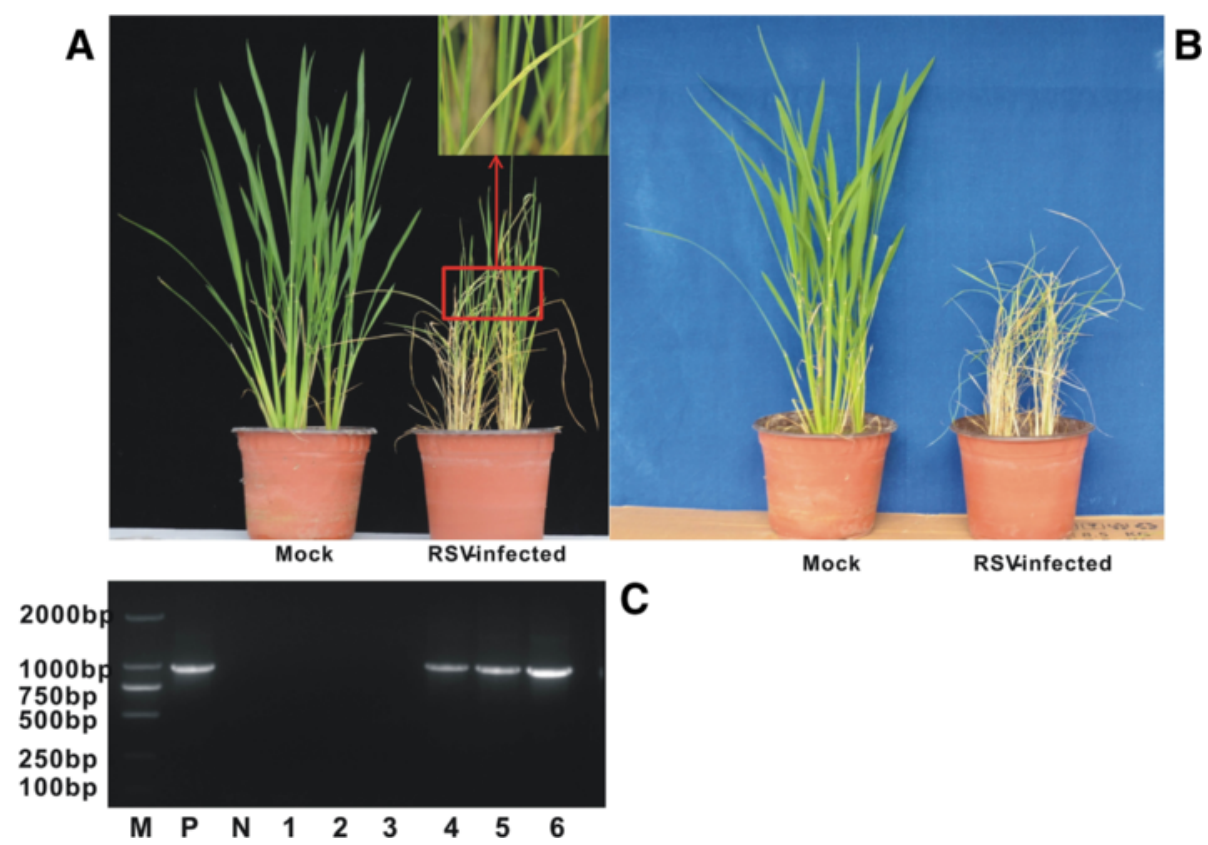

Fig. 1 Typical chlorotic stripes and necrosis symptoms in rice plants induced by Rice stripe virus (RSV) and infection confirmation by RT-PCR detection. Both RSV-infected and mock rice plants were shown at (a) 21 days post inoculation (dpi) and (b) 23 dpi; (c) RT-PCR confirming that 969-bp fragment for RSV nucleocapsid gene (NCP) was absent in mock and present in symptomatic RSV-infected plants. Mock rice had typical healthy growth, but RSV-infected leaves showed typical chlorosis at 21 dpi (corner of panel a), and the entire plant was dead at 23 dpi (b). M, DL2000 DNA marker; P, RSV infected sample as positive control; N, healthy sample as negative control; 1-3, mock leaves; 4-6, RSV-infected leaves

biosynthesis (16.3\%), photosynthesis (12.3\%), generation of precursor metabolites and energy (11.8\%), cofactor metabolism (10.8\%), translation (9.9\%), monosaccharide metabolism (9.4\%), hexose metabolism (8.4\%), carboxylic acid biosynthesis (8.4\%), glucose metabolism (7.9\%) (Fig. 3a, Additional file 1: Table S1). The other 112 (62.9\%, 17 groups) upregulated proteins were mostly involved in oxidation reduction $(25.0 \%)$, proteolysis $(17.0 \%)$, generation of precursor metabolites and energy (12.5\%), macromolecule catabolism (11.6\%), protein catabolism (10.7\%), cellular protein catabolism (8.9\%), cofactor metabolism $(8.0 \%)$, cellular homeostasis (8.0\%), protein folding $(6.3 \%)$, and carbohydrate catabolism (6.3 \%) (Fig. 3b, Additional file 1: Table S1). Cellular components that were downregulated included 154 proteins (46.4\%, 20 component groups), located in the plastid (70.8\%), chloroplast (31.8\%), thylakoid (12.3\%), photosynthetic membrane (9.1\%), organellar membrane $(9.1 \%)$, thylakoid part $(7.8 \%)$, plastid part (7.8\%), photosystem (6.5\%), chloroplast part (5.2\%), extrinsic to membrane (5.2\%), and oxygen evolving complex (4.5 \%) (Fig. 3a, Additional file 1: Table S1). The 64 (36.0\%, 13 component groups) upregulated proteins were located in the cytosol (17.2\%), proteasome complex (15.6\%), organelle membrane (12.5\%), proteasome core complex (10.9\%), endoplasmic reticulum (9.4\%), Golgi apparatus (9.4\%), envelope (7.8\%), mitochondrial membrane (6.3\%), ribosomal subunit (4.7\%), membrane coat (4.7 \%), and cell junction (3.1\%) (Fig. 3b, Additional file 1: Table S1).

The KEGG pathway analyses indicated that among the downregulated proteins, $13 \%$ were involved in the biosynthesis of plant hormones; $9 \%$ in photosynthesis, carbon fixation in photosynthetic organisms, biosynthesis of terpenoids and steroid; and $4 \%$ in porphyrin and chlorophyll metabolism (Fig. 4a). However, among the upregulated proteins, $16 \%$ were involved in biosynthesis of plant hormones, $11 \%$ in biosynthesis of alkaloids derived from shikimate pathway, $10 \%$ in biosynthesis of phenylpropanoids, and $9 \%$ in proteasome, starch and sucrose metabolism, citrate cycle, tryptophan metabolism, fatty acid metabolism, propanoate metabolism, and pentose and glucuronate interconversions (Fig. 4b). When the identified proteins were analyzed with the STRING software, the results showed that 547 proteins were interacting with each other. In the constructed interaction network (Additional file 2: Figure S1), the proteins were roughly divided into three groups: metabolism (B), chloroplast (C) and defense (D).

\section{Proteins differentially accumulated in response to RSV infection}

\section{Metabolism group}

Functions of the down- and up-regulated differentially accumulated metabolism group of proteins included 


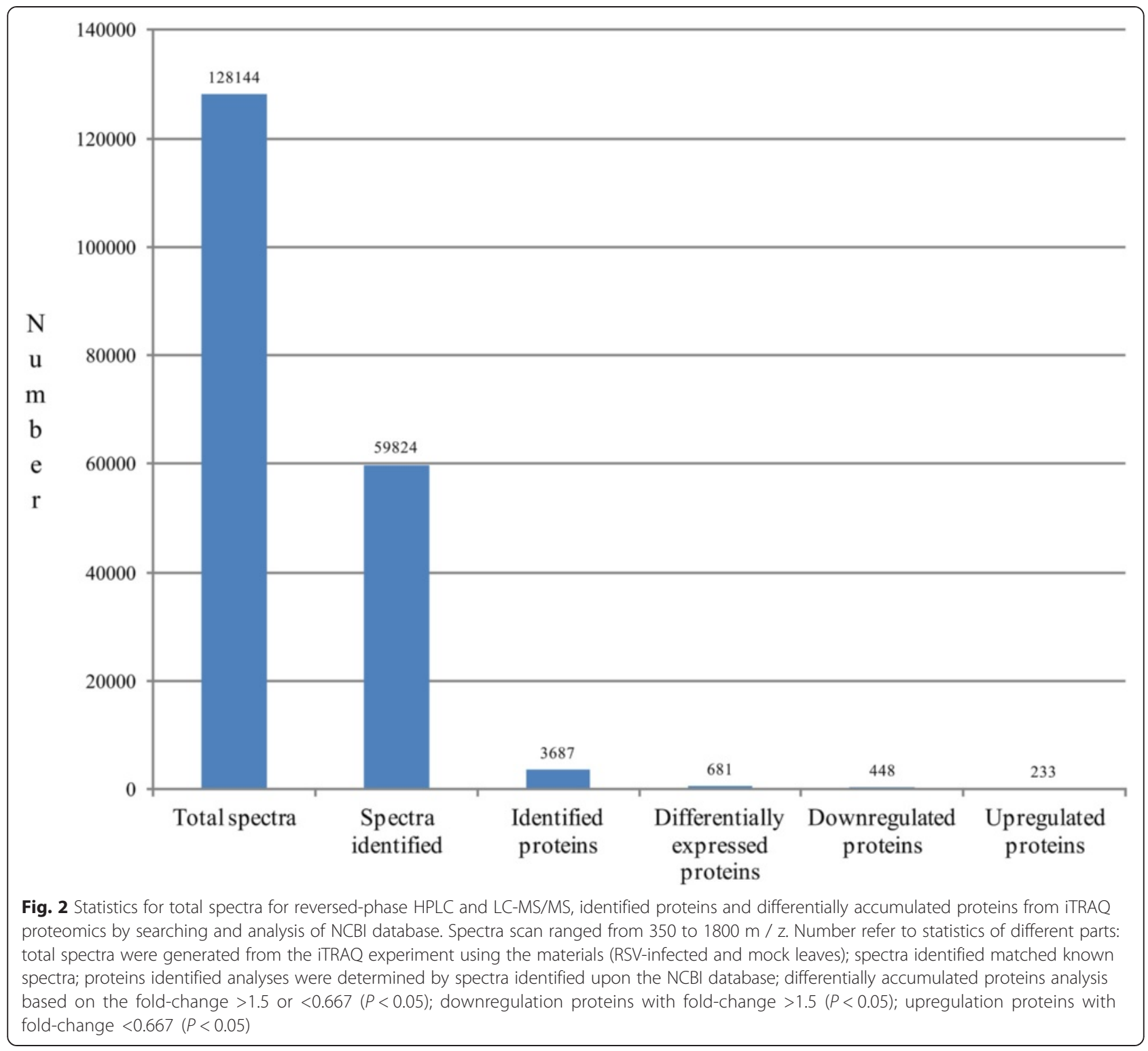

monosaccharide metabolism, disaccharide metabolism, polysaccharide metabolism, generation of precursor metabolites and energy, amino acid metabolism, fatty acid metabolism, phosphorus metabolism, and sulfur metabolism. Basically, carbohydrate metabolism provided more suitable source of energy and carbon for plant development. For example, glyceraldehyde-3-phosphate dehydrogenase (GAPDH; 115458768, 115450493) and fructose-bisphosphate aldolase (115484401, 115468886, 115434198) were two important metabolic enzymes in glycolysis and gluconeogenesis [31]. Notable, evidences increasingly support the nonglycolytic functions of GAPDH, including apoptosis, DNA and RNA replication, DNA repair, RNA exportation, RNA synthesis, immunity response to various pathogens [32-38]. GAPDH strong binding of negative strand Tomato bushy stunt virus (TBSV) was key regulatory step to promote asymmetric RNA synthesis, so GAPDH played a role in viral RNA replication and RNA synthesis [34]. However, GAPDH preferentially binds positive strand Bamboo mosaic virus (BaMV), and it negatively regulated the accumulation of BaMV [35]. Additionally, GAPDH negatively regulate autophagy interaction with host protein and immunity-associated cell death and defense on TMV infection [38]. GAPDH may be involved in viral replication and defense during RSV infection. Proteins that decreased in expression belonged to the vitamin, nucleotide, isoprenoid, phosphorus, sulfur and cofactor metabolism groups, suggesting that RSV infection inhibited their expression (Table 2). Thus, numerous biological processes helped rice to counteract RSV invasion. 
Table 1 Summary of the proteins identified by iTRAQ as being differentially accumulated in RSV-inoculated plants compared with mock-inoculated rice plants at $21 \mathrm{dpi}$

\begin{tabular}{|c|c|c|c|c|c|c|}
\hline Regulation & No. of proteins & David & $\mathrm{GO}^{\mathrm{a}}$ & Categories $^{\mathrm{b}}$ & Percentage $^{c}$ & No. of functional groups \\
\hline \multirow[t]{5}{*}{ Down } & $448(65.8 \%)$ & 332 & 317 & $203 \mathrm{BP}$ & 61.1 & 53 \\
\hline & & & & 154 CC & 46.4 & 20 \\
\hline & & & & $233 \mathrm{MF}$ & 70.2 & 33 \\
\hline & & & & 129 KEGG & 38.9 & 16 \\
\hline & & unknov & & & & \\
\hline \multirow[t]{5}{*}{ Up } & $233(34.2 \%)$ & 178 & 175 & $112-B P$ & 62.9 & 17 \\
\hline & & & & 64 CC & 36.0 & 13 \\
\hline & & & & $125 \mathrm{MF}$ & 70.2 & 16 \\
\hline & & & & 7 -KEGG & 39.9 & 13 \\
\hline & & unknov & & & & \\
\hline Total & 681 & & & & & \\
\hline
\end{tabular}

\section{Chloroplast group}

The 30 annotated significantly downregulated proteins in the chloroplast group process were involved in chlorophyll biosynthesis and photosynthesis (Table 2). For chlorophyll biosynthesis, 10 proteins involved in the chlorophyll contents in RSV-infected leaves were more than 3 times lower than in the mock leaves: magnesium chelatase subunit I (CHLI) and subunit D (CHLD), magnesium-protoporphyrin IX monomethyl ester [oxidative] cyclase, uroporphyrinogen decarboxylase 1, uroporphyrinogen decarboxylase 2, protoporphyrinogen oxidase, porphobilinogen deaminase, delta-aminolevulinic acid dehydratase, glutamate-1-semialdehyde 2,1-aminomutase, glutamyl-tRNA reductase (Table 2; Fig. 5). Twenty photosynthesis proteins were also annotated as enriched, whereas four oxygen-evolving enhancer proteins and a type protein involved in the chloroplast biosynthesis were over 10 times lower upon RSV infection than those in the mock control. Meanwhile, five chlorophyll a/b-binding proteins were downregulated in RSV-infected leaves compared with mock leaves (Table 2). Thus, the accumulation of 30 proteins in the chlorophyll metabolism was apparently reduced by RSV infection.

\section{Defense group}

Leaves are the primary tissue for RSV infection and colonization, so not surprisingly, four defensive proteins in RSV-infected leaves were identified as being altered in accumulation. Three pathogenesis-related proteins and a Bet v 1 allergen family protein were significantly more abundant in RSV-infected leaves than those in mock leaves: pathogenesis-related protein 1, pathogenesisrelated protein 10, pathogenesis-related protein and Bet v I allergen family protein (Table 2). The upregulation of those proteins indicated that defensive reactions were induced after inoculation with RSV. From the $70 \mathrm{kDa}$ heat shock protein (HSP70) family, ubiquitous in plants in response to diverse DNA and RNA viruses [39, 40], HSP70 and HSP (putative heat shock protein) were expressed at high levels in RSV-infected leaves compared with mock leaves, indicating that RSV activates the expression of the genes encoding HSP. In addition, superoxide dismutase $[\mathrm{Mn}]$ and four peroxidases expressed were upregulated in response to RSV (Table 2).

Of 28 annotated proteins involved in proteolysis, 19 proteins increased in response to RSV infection: 7 proteasome subunits, 3 ubiquitin type proteins, 3 aspartic type proteins, 2 aminopeptidase M1 subunits, 1 DNA-binding protein, 1 leukotriene A-4 hydrolase, 1 serine carboxypeptidase and 1 insulin degrading enzyme. Three aspartic type proteins (eukaryotic aspartyl protease family protein, aspartic proteinase and peptidase aspartic) were expressed at a high level in the RSV-infected leaves (Table 2).

\section{Validation of changes in RNA level by RT-qPCR and Northern blotting}

Based on a proteomics analysis, the proteins differentially accumulated during RSV infection, key proteins for chlorophyll biosynthesis and an aspartic-type endopeptidase were identified as involved in the formation of RSV induced symptoms, and their presence was quantitatively confirmed using RT-qPCR and Northern blot to evaluate the correlation between mRNA and protein levels. Total RNA extracted from RSV-infected and mock leaves was analyzed to measure mRNA transcription levels of putative target proteins. The RT-qPCR 


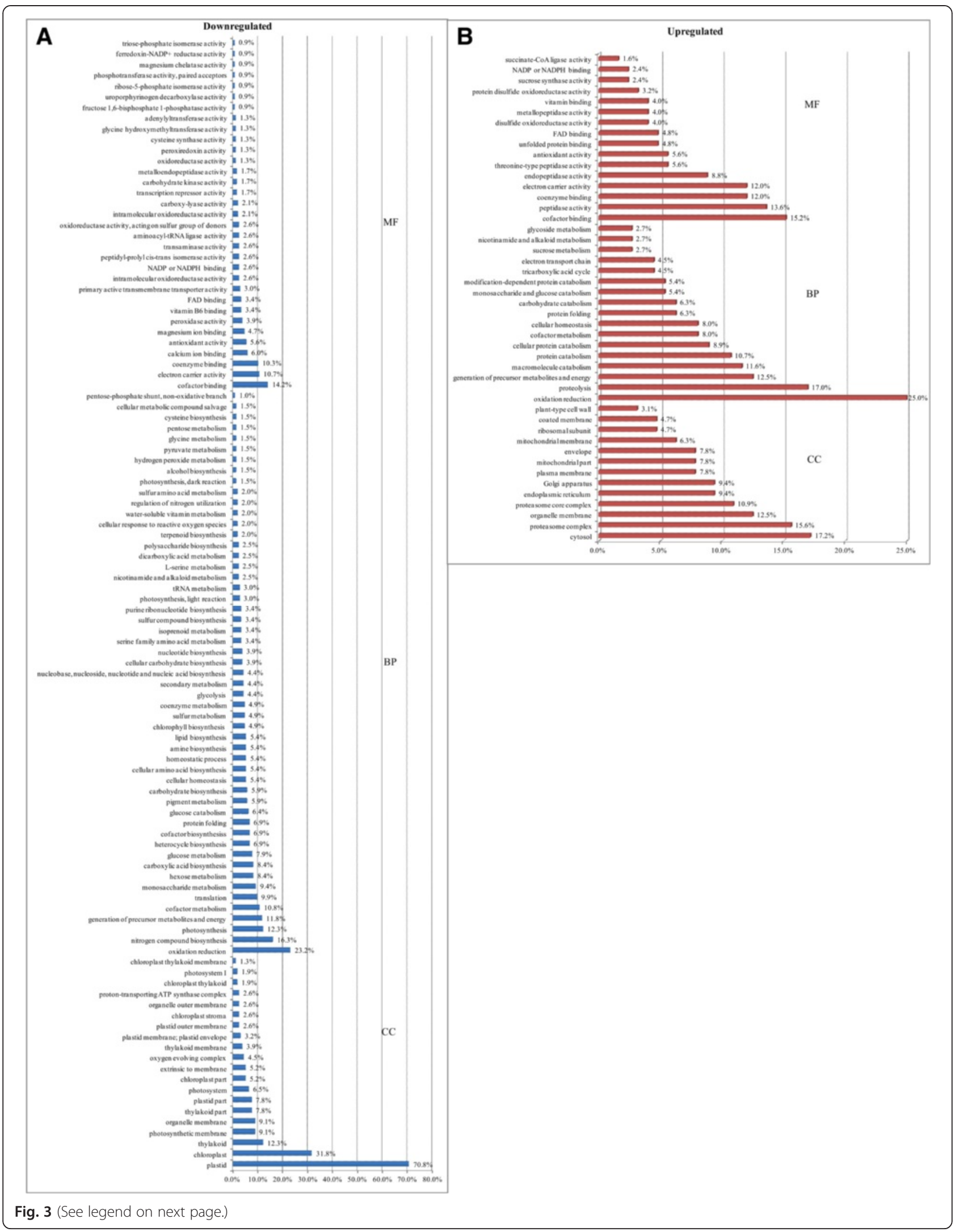


(See figure on previous page.)

Fig. 3 Gene Ontology enrichment analysis of differentially accumulated proteins from RSV-infected leaves compared with mock leaves. a Downregulated differentially accumulated proteins were annotated among 33 groups for molecular function (MF), 53 for biological process (BP) and 20 for cellular components (CC), respectively; b, Functional grouping of upregulated differentially accumulated proteins: 16 for MF, 17 for BP and 13 for CC

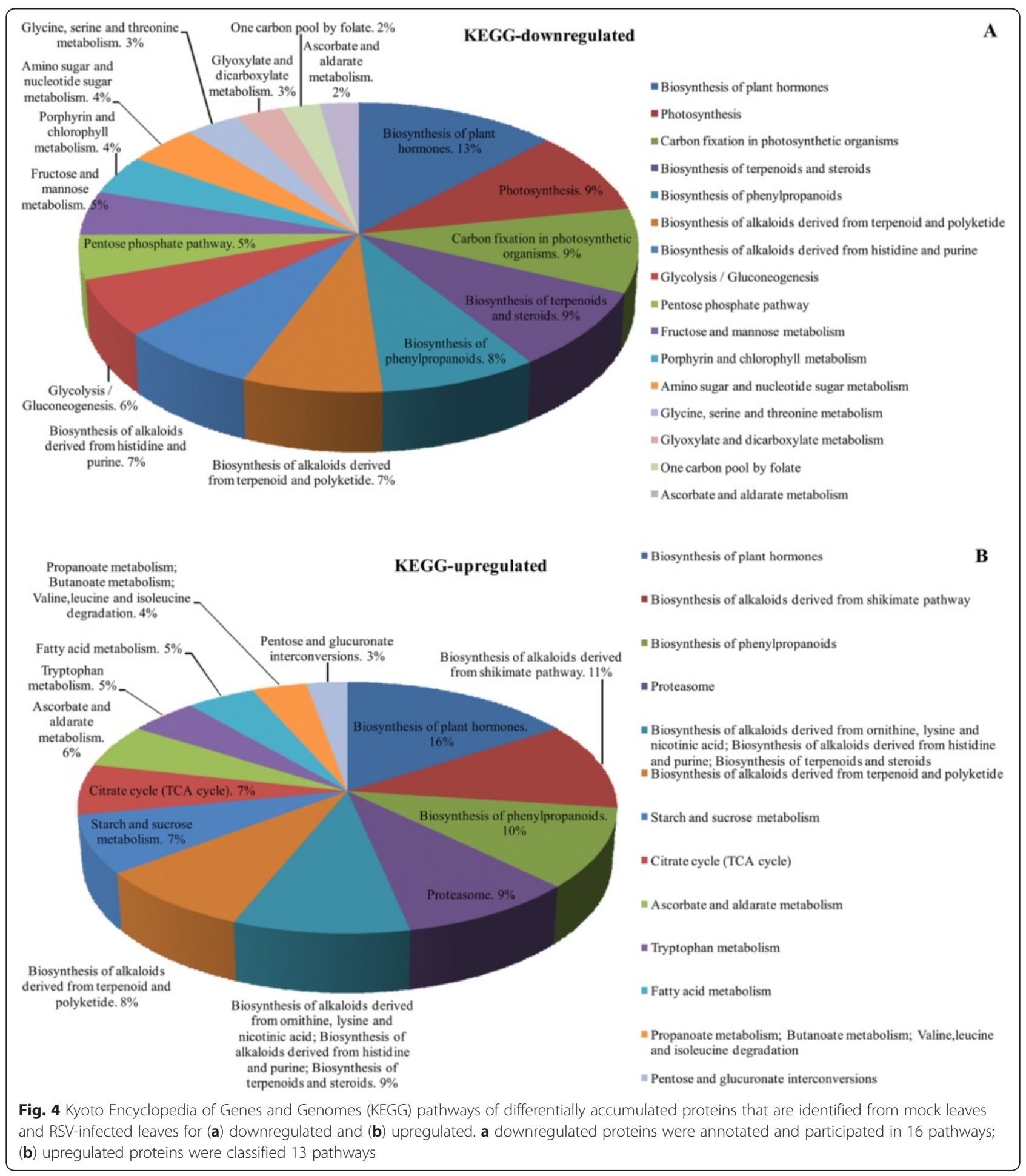


Table 2 Differentially accumulated proteins between mock-inoculated leaves and RSV-infected leaves

\begin{tabular}{|c|c|c|c|c|c|}
\hline Accession number & Protein name categorized by process & $\operatorname{Cov}(95)$ & $\begin{array}{l}\text { Number of } \\
\text { Matching Peptides }\end{array}$ & Ratio & $P$-Value \\
\hline & Chlorophyll biosynthetic process & & & & \\
\hline 115453785 & Magnesium-chelatase subunit Chll, chloroplastic & 46.7 & 29 & 17.5 & $4.50 \times 10^{-8}$ \\
\hline 115438661 & Uroporphyrinogen decarboxylase 1 , chloroplastic & 14.9 & 8 & 13.4 & $2.85 \times 10^{-2}$ \\
\hline 115444475 & Porphobilinogen deaminase, chloroplastic & 51.1 & 21 & 11.7 & $4.50 \times 10^{-4}$ \\
\hline 115456135 & Magnesium-chelatase subunit ChID, chloroplastic & 27.8 & 23 & 9.4 & $5.19 \times 10^{-7}$ \\
\hline 115477483 & Glutamate-1-semialdehyde 2,1-aminomutase, chloroplastic & 34.7 & 26 & 5.3 & $2.85 \times 10^{-2}$ \\
\hline 115452897 & Uroporphyrinogen decarboxylase 2, chloroplastic & 36.4 & 21 & 5.0 & $1.83 \times 10^{-2}$ \\
\hline 115436038 & Protoporphyrinogen oxidase, chloroplastic & 21.3 & 12 & 4.8 & $3.07 \times 10^{-4}$ \\
\hline 115435974 & Magnesium-protoporphyrin IX monomethyl ester [oxidative] cyclase & 42.2 & 25 & 3.7 & $1.16 \times 10^{-5}$ \\
\hline 115469822 & Delta-aminolevulinic acid dehydratase, chloroplastic & 29.1 & 16 & 3.5 & $4.11 \times 10^{-4}$ \\
\hline \multirow[t]{2}{*}{115482796} & Glutamyl-tRNA reductase, chloroplastic & 16.4 & 9 & 3.4 & $1.34 \times 10^{-3}$ \\
\hline & Photosynthesis & & & & \\
\hline 109156602 & Ribulose bisphosphate carboxylase large chain & 82.2 & 508 & 44.1 & $1.71 \times 10^{-5}$ \\
\hline 115472625 & Oxygen-evolving enhancer protein 3 & 41.5 & 57 & 31.9 & $3.46 \times 10^{-5}$ \\
\hline 115436780 & Putative $33 \mathrm{kDa}$ oxygen evolving protein of photosystem II & 59.2 & 119 & 28.3 & $2.30 \times 10^{-10}$ \\
\hline 115470529 & Probable photosystem II oxygen-evolving complex protein 2 & 58.3 & 62 & 21.1 & $8.92 \times 10^{-4}$ \\
\hline 115488344 & Photosystem I reaction center subunit XI, chloroplast & 30.8 & 13 & 19.1 & $3.57 \times 10^{-2}$ \\
\hline 115472753 & Chlorophyll a/b-binding protein & 49.0 & 39 & 18.7 & $8.07 \times 10^{-4}$ \\
\hline 115477831 & Chloroplast photosystem I reaction center subunit II-like protein & 59.1 & 50 & 18.4 & $3.46 \times 10^{-7}$ \\
\hline 115476576 & Putative chlorophyll a/b-binding protein & 36.5 & 27 & 14.5 & $2.05 \times 10^{-2}$ \\
\hline 115458738 & OSJNBa0036B21.6 protein & 38.5 & 19 & 13.7 & $2.74 \times 10^{-4}$ \\
\hline 115484899 & Chlorophyll a/b-binding protein & 63.2 & 67 & 13.3 & $1.17 \times 10^{-5}$ \\
\hline 115470199 & PsbQ domain protein family, putative-like protein & 28.4 & 11 & 10.9 & $1.53 \times 10^{-3}$ \\
\hline 115472785 & Putative chlorophyll a/b-binding protein of LHCII type III, chloroplast & 50.4 & 20 & 10.4 & $4.90 \times 10^{-3}$ \\
\hline 115446893 & Putative Oxygen-evolving enhancer protein 3-2, chloroplast & 26.2 & 6 & 10.1 & $2.74 \times 10^{-2}$ \\
\hline 115487694 & Photosystem I reaction centre subunit $\mathrm{N}$, chloroplast & 28.2 & 8 & 10.0 & $2.12 \times 10^{-2}$ \\
\hline 115450991 & Ribulose-phosphate 3-epimerase, chloroplastic & 50.0 & 28 & 7.8 & $8.74 \times 10^{-4}$ \\
\hline 115467828 & Chlorophyll a/b-binding protein & 31.1 & 27 & 7.8 & $6.31 \times 10^{-3}$ \\
\hline 115452127 & Fructose-1,6-bisphosphatase, chloroplastic & 38.9 & 45 & 6.8 & $5.54 \times 10^{-6}$ \\
\hline 115482366 & PsbP family protein & 18.1 & 16 & 5.6 & $1.14 \times 10^{-3}$ \\
\hline 115465942 & Ferredoxin-NADP reductase, leaf isozyme, chloroplastic & 49.7 & 66 & 5.4 & $5.64 \times 10^{-3}$ \\
\hline \multirow[t]{2}{*}{115447507} & Putative ferredoxin-thioredoxin reductase & 20.1 & 4 & 2.5 & $2.91 \times 10^{-2}$ \\
\hline & Defense response & & & & \\
\hline 115458852 & Bet $v$ I allergen family protein & 29.9 & 5 & 0.3 & $1.89 \times 10^{-3}$ \\
\hline 115452513 & Pathogenesis-related protein 1 & 49.4 & 7 & 0.1 & $7.92 \times 10^{-4}$ \\
\hline 115489022 & Pathogenesis-related protein & 29.8 & 5 & 0.04 & $9.16 \times 10^{-4}$ \\
\hline \multirow[t]{2}{*}{115489014} & Pathogenesis-related protein PR10 & 25.6 & 4 & 0.03 & $1.88 \times 10^{-2}$ \\
\hline & Proteolysis & & & & \\
\hline 115470052 & ATP-dependent zinc metalloprotease FTSH 1, chloroplastic & 42.6 & 50 & 9.9 & $3.31 \times 10^{-8}$ \\
\hline 115453893 & Membrane-associated zinc metalloprotease family protein & 17.6 & 7 & 7.7 & $8.99 \times 10^{-4}$ \\
\hline 115489316 & Eukaryotic aspartyl protease family protein & 25.1 & 10 & 6.8 & $1.04 \times 10^{-2}$ \\
\hline 115447609 & ATP-dependent zinc metalloprotease FTSH 7, chloroplastic & 4.3 & 4 & 6.5 & $3.77 \times 10^{-2}$ \\
\hline 115480844 & Serine carboxypeptidase family protein & 13.3 & 8 & 5.6 & $3.69 \times 10^{-2}$ \\
\hline
\end{tabular}


Table 2 Differentially accumulated proteins between mock-inoculated leaves and RSV-infected leaves (Continued)

\begin{tabular}{|c|c|c|c|c|c|}
\hline 115435898 & ATP-dependent Clp protease proteolytic subunit & 18.5 & 4 & 3.5 & $2.12 \times 10^{-2}$ \\
\hline 115450022 & Oligopeptidase A-like & 24.2 & 20 & 3.2 & $1.35 \times 10^{-4}$ \\
\hline 115452585 & Probable glutamyl endopeptidase, chloroplastic & 15.0 & 18 & 2.9 & $6.00 \times 10^{-3}$ \\
\hline 115488046 & Serine carboxypeptidase 1 & 11.2 & 4 & 2.7 & $4.20 \times 10^{-2}$ \\
\hline 115444859 & Peptidase aspartic & 24.1 & 10 & 0.5 & $4.99 \times 10^{-2}$ \\
\hline 115437452 & Ubiquitin carboxyl-terminal hydrolase & 16.2 & 7 & 0.4 & $3.60 \times 10^{-2}$ \\
\hline 115482252 & Ubiquitin-conjugating enzyme E2-23 kDa & 20.1 & 3 & 0.4 & $1.14 \times 10^{-2}$ \\
\hline 115483755 & Ubiquitin-activating enzyme E1 2 & 22.6 & 25 & 0.4 & $3.41 \times 10^{-3}$ \\
\hline 115463349 & Putative DNA-binding protein GBP16 & 26.0 & 15 & 0.4 & $1.26 \times 10^{-2}$ \\
\hline 115454751 & Proteasome subunit beta type-2 & 30.2 & 9 & 0.4 & $2.65 \times 10^{-2}$ \\
\hline 115465685 & Putative serine carboxypeptidase & 24.9 & 12 & 0.4 & $4.19 \times 10^{-3}$ \\
\hline 115451123 & Proteasome subunit alpha type- 6 & 43.1 & 13 & 0.3 & $1.22 \times 10^{-3}$ \\
\hline 115456219 & Leukotriene A-4 hydrolase homolog & 20.8 & 12 & 0.3 & $6.69 \times 10^{-3}$ \\
\hline 115480143 & Proteasome subunit beta type & 36.3 & 7 & 0.3 & $1.63 \times 10^{-2}$ \\
\hline 115444057 & Proteasome subunit alpha type-1 & 40.0 & 13 & 0.3 & $1.08 \times 10^{-2}$ \\
\hline 115440299 & Putative insulin degrading enzyme & 3.0 & 2 & 0.3 & $2.91 \times 10^{-2}$ \\
\hline 115440617 & Proteasome subunit alpha type-3 & 39.4 & 10 & 0.3 & $4.04 \times 10^{-2}$ \\
\hline 115480019 & Proteasome subunit beta type-1 & 28.1 & 6 & 0.2 & $7.50 \times 10^{-3}$ \\
\hline 115448935 & Proteasome subunit beta type & 40.7 & 12 & 0.2 & $6.34 \times 10^{-4}$ \\
\hline 115476300 & Aminopeptidase M1-B & 22.7 & 19 & 0.2 & $8.85 \times 10^{-5}$ \\
\hline 115461973 & Aspartic proteinase & 23.8 & 11 & 0.2 & $3.50 \times 10^{-3}$ \\
\hline 115445047 & Aminopeptidase M1-A & 18.8 & 17 & 0.2 & $1.04 \times 10^{-5}$ \\
\hline \multirow[t]{2}{*}{115451209} & Eukaryotic aspartyl protease family protein & 11.4 & 4 & 0.2 & $2.37 \times 10^{-3}$ \\
\hline & Protein transport & & & & \\
\hline 115475569 & Preprotein translocase subunit SECY, chloroplastic & 4.1 & 3 & 5.5 & $1.76 \times 10^{-3}$ \\
\hline 115454153 & SEC1 family transport protein SLY1 & 8.0 & 4 & 5.3 & $1.93 \times 10^{-2}$ \\
\hline 115451815 & Translocase of chloroplast & 20.2 & 7 & 3.1 & $1.42 \times 10^{-2}$ \\
\hline 115452177 & Protein TOC75, chloroplastic & 34.4 & 25 & 2.9 & $3.10 \times 10^{-6}$ \\
\hline 115435528 & Importin-alpha re-exporter & 5.5 & 2 & 0.5 & $7.40 \times 10^{-4}$ \\
\hline 115435714 & GTP-binding protein & 21.2 & 3 & 0.3 & $4.33 \times 10^{-2}$ \\
\hline 115463933 & Putative GDP dissociation inhibitor & 30.8 & 16 & 0.3 & $3.53 \times 10^{-5}$ \\
\hline 115454911 & Coatomer subunit alpha-1 & 22.6 & 25 & 0.3 & $4.93 \times 10^{-5}$ \\
\hline 115461356 & Clathrin light chain 1 & 14.6 & 3 & 0.2 & $4.25 \times 10^{-2}$ \\
\hline \multirow[t]{2}{*}{115463119} & Coatomer subunit delta-1 & 11.5 & 7 & 0.2 & $1.90 \times 10^{-3}$ \\
\hline & Translation & & & & \\
\hline 115480611 & Cysteinyl-tRNA synthetase & 11.8 & 6 & 8.7 & $1.93 \times 10^{-3}$ \\
\hline 115450395 & $50 S$ ribosomal protein L11, chloroplast & 38.1 & 13 & 7.2 & $2.71 \times 10^{-2}$ \\
\hline 115488938 & Elongation factor Ts & 25.6 & 45 & 6.7 & $1.06 \times 10^{-9}$ \\
\hline 115436768 & Tyrosine-tRNA ligase & 22.3 & 12 & 6.6 & $3.46 \times 10^{-3}$ \\
\hline 115472897 & Ribosome-recycling factor, chloroplastic & 31.2 & 17 & 6.6 & $1.13 \times 10^{-3}$ \\
\hline 115449027 & Putative isoleucyl-tRNA synthetase & 8.2 & 8 & 6.3 & $1.95 \times 10^{-6}$ \\
\hline 115470767 & Probable polyribonucleotide nucleotidyltransferase 1 , chloroplastic & 9.6 & 10 & 6.1 & $4.16 \times 10^{-4}$ \\
\hline 115445399 & Putative 50 S ribosomal protein $L 21$, chloroplast & 25.7 & 7 & 5.8 & $1.12 \times 10^{-2}$ \\
\hline 115489150 & $60 S$ ribosomal protein $L 2$ & 30.6 & 11 & 4.8 & $6.71 \times 10^{-3}$ \\
\hline 115486501 & Peptide chain release factor 1 & 17.8 & 7 & 4.7 & $4.88 \times 10^{-4}$ \\
\hline
\end{tabular}


Table 2 Differentially accumulated proteins between mock-inoculated leaves and RSV-infected leaves (Continued)

\begin{tabular}{|c|c|c|c|c|c|}
\hline 50233964 & 30 S ribosomal protein $\mathrm{S} 2$, chloroplastic & 25.9 & 10 & 4.5 & $8.95 \times 10^{-4}$ \\
\hline 115438779 & Peptide deformylase 1B, chloroplastic & 16.4 & 5 & 4.1 & $4.50 \times 10^{-2}$ \\
\hline 115458788 & OSJNBa0072F16.12 protein & 21.3 & 5 & 3.9 & $4.05 \times 10^{-2}$ \\
\hline 115450427 & $50 S$ ribosomal protein $L 5$, chloroplastic & 42.6 & 17 & 3.9 & $1.43 \times 10^{-3}$ \\
\hline 115448755 & Putative histidine-tRNA ligase & 6.6 & 4 & 3.8 & $4.60 \times 10^{-2}$ \\
\hline 115451609 & 50 S ribosomal protein L15, chloroplast & 29.7 & 11 & 3.5 & $3.81 \times 10^{-2}$ \\
\hline 115446545 & Putative threonyl-tRNA synthetase & 14.1 & 9 & 2.9 & $1.25 \times 10^{-6}$ \\
\hline 115439267 & Met-tRNAi formyl transferase-like & 20.7 & 6 & 2.8 & $2.49 \times 10^{-3}$ \\
\hline 115465593 & Translation initiation factor IF-2 & 14.3 & 7 & 2.5 & $4.04 \times 10^{-2}$ \\
\hline 115463659 & Putative chloroplast ribosomal protein L1 & 30.6 & 24 & 2.4 & $1.55 \times 10^{-3}$ \\
\hline 115487526 & 605 ribosomal protein $\mathrm{L} 3$ & 29.3 & 17 & 2.1 & $1.93 \times 10^{-2}$ \\
\hline 115447385 & Lysine-tRNA ligase & 14.5 & 9 & 1.5 & $4.36 \times 10^{-2}$ \\
\hline 115488928 & Tryptophanyl-tRNA synthetase & 21.8 & 7 & 0.5 & $4.03 \times 10^{-2}$ \\
\hline 115453877 & 40 S ribosomal protein $\mathrm{S3}$ & 44.7 & 14 & 0.5 & $2.32 \times 10^{-3}$ \\
\hline 115487104 & $40 \mathrm{~S}$ ribosomal protein S16 & 27.5 & 6 & 0.4 & $1.16 \times 10^{-2}$ \\
\hline 115434960 & Putative tRNA-glutamine synthetase & 11.2 & 8 & 0.3 & $7.99 \times 10^{-3}$ \\
\hline 115473889 & Elongation factor 1-beta & 39.7 & 21 & 0.3 & $1.27 \times 10^{-2}$ \\
\hline 115486179 & $40 S$ ribosomal protein $\$ 9$ & 26.2 & 6 & 0.3 & $2.61 \times 10^{-3}$ \\
\hline \multirow[t]{2}{*}{115475427} & Putative 605 ribosomal protein $\mathrm{L7}$ & 22.5 & 9 & 0.2 & $2.22 \times 10^{-2}$ \\
\hline & Protein folding & & & & \\
\hline 115444001 & Putative uncharacterized protein P0576F08.31 & 16.7 & 6 & 22.9 & $1.64 \times 10^{-4}$ \\
\hline 115458444 & GrpE protein homolog & 26.6 & 9 & 18.2 & $1.12 \times 10^{-2}$ \\
\hline 115476198 & Putative peptidyl-prolyl cis-trans isomerase, chloroplast & 34.3 & 21 & 14.9 & $5.61 \times 10^{-5}$ \\
\hline 115449059 & Putative 20 kDa chaperonin, chloroplast & 46.3 & 9 & 8.2 & $1.49 \times 10^{-2}$ \\
\hline 115461585 & Peptidyl-prolyl cis-trans isomerase & 39.2 & 23 & 7.7 & $3.33 \times 10^{-3}$ \\
\hline 115460872 & OSJNBb0079B02.1 protein & 4.6 & 3 & 6.1 & $2.96 \times 10^{-2}$ \\
\hline 115467746 & Trigger factor-like & 39.5 & 27 & 4.8 & $1.77 \times 10^{-4}$ \\
\hline 115472829 & Putative peptidyl-proly cis-trans isomerase protein & 29.2 & 20 & 4.7 & $5.14 \times 10^{-5}$ \\
\hline 115448437 & Putative protease IV & 14.5 & 10 & 4.7 & $6.37 \times 10^{-3}$ \\
\hline 115472151 & Peptidyl-prolyl cis-trans isomerase & 23.3 & 5 & 4.6 & $4.48 \times 10^{-2}$ \\
\hline 115488160 & $60 \mathrm{kDa}$ chaperonin alpha subunit & 55.5 & 64 & 3.8 & $5.70 \times 10^{-5}$ \\
\hline 115473507 & Receptor protein kinase & 11.7 & 8 & 3.8 & $1.55 \times 10^{-2}$ \\
\hline 115466004 & Putative chaperonin 60 beta & 48.2 & 63 & 3.7 & $1.65 \times 10^{-3}$ \\
\hline 115475740 & Putative uncharacterized protein OSJNBb0075018.114 & 23.2 & 6 & 3.6 & $6.47 \times 10^{-3}$ \\
\hline 115465267 & Serine/threonine-protein kinase SNT7 & 13.6 & 8 & 3.4 & $1.46 \times 10^{-2}$ \\
\hline 115448713 & Peptidyl-prolyl cis-trans isomerase & 34.3 & 11 & 3.1 & $8.95 \times 10^{-4}$ \\
\hline 115484731 & $A B C-1$ domain containing protein & 9.0 & 7 & 2.9 & $1.57 \times 10^{-2}$ \\
\hline 115441683 & ABC1-like & 5.3 & 3 & 2.8 & $4.11 \times 10^{-2}$ \\
\hline 115477014 & Putative heat-shock protein & 21.0 & 17 & 2.5 & $1.11 \times 10^{-2}$ \\
\hline 115463261 & Putative DnaJ protein & 25.3 & 14 & 2.5 & $4.82 \times 10^{-3}$ \\
\hline 115487998 & $70 \mathrm{kDa}$ heat shock protein & 45.4 & 60 & 2.3 & $1.13 \times 10^{-2}$ \\
\hline 115469982 & Endoplasmin homolog precursor & 26.7 & 28 & 0.5 & $1.62 \times 10^{-2}$ \\
\hline 115456045 & T-complex protein 1, theta subunit & 34.1 & 17 & 0.4 & $1.77 \times 10^{-2}$ \\
\hline 115462083 & Chaperonin protein & 19.4 & 11 & 0.3 & $3.37 \times 10^{-2}$ \\
\hline 115471369 & Calreticulin & 19.8 & 9 & 0.2 & $1.11 \times 10^{-2}$ \\
\hline
\end{tabular}


Table 2 Differentially accumulated proteins between mock-inoculated leaves and RSV-infected leaves (Continued)

\begin{tabular}{|c|c|c|c|c|c|}
\hline 115477393 & Putative $70 \mathrm{kDa}$ peptidylprolyl isomerase & 15.3 & 9 & 0.2 & $3.70 \times 10^{-4}$ \\
\hline 115468394 & T-complex protein 1 subunit gamma & 21.3 & 12 & 0.2 & $1.36 \times 10^{-3}$ \\
\hline \multirow[t]{2}{*}{115458184} & Calnexin & 26.6 & 15 & 0.2 & $4.69 \times 10^{-4}$ \\
\hline & Monosaccharide metabolism & & & & \\
\hline 115458768 & Glyceraldehyde-3-phosphate dehydrogenase & 63.4 & 120 & 22.5 & $1.98 \times 10^{-4}$ \\
\hline 115484401 & Fructose-bisphosphate aldolase, chloroplastic & 74.0 & 126 & 22.1 & $4.10 \times 10^{-7}$ \\
\hline 115468886 & Fructose-bisphosphate aldolase & 57.3 & 49 & 20.5 & $8.04 \times 10^{-7}$ \\
\hline 115455637 & Malate dehydrogenase & 67.0 & 35 & 12.6 & $8.32 \times 10^{-4}$ \\
\hline 115450493 & Glyceraldehyde-3-phosphate dehydrogenase & 57.2 & 91 & 7.7 & $2.32 \times 10^{-5}$ \\
\hline 115466256 & Putative enolase & 46.0 & 32 & 7.3 & $1.48 \times 10^{-2}$ \\
\hline 115470849 & Putative ribose-5-phosphate isomerase & 52.5 & 32 & 5.6 & $1.19 \times 10^{-2}$ \\
\hline 115477891 & PfkB type carbohydrate kinase protein family-like & 12.1 & 4 & 5.3 & $1.34 \times 10^{-2}$ \\
\hline 115434516 & Triosephosphate isomerase, cytosolic & 69.2 & 29 & 5.0 & $4.75 \times 10^{-2}$ \\
\hline 115462281 & Fructose-6-phosphate 2-kinase/fructose-2,6-bisphosphatase & 22.9 & 20 & 5.0 & $8.62 \times 10^{-8}$ \\
\hline 115479643 & Glucose-6-phosphate isomerase & 29.9 & 19 & 4.8 & $3.56 \times 10^{-4}$ \\
\hline 115457638 & OSJNBa0023J03.8 protein & 31.3 & 8 & 4.5 & $2.00 \times 10^{-2}$ \\
\hline 115455133 & 4-hydroxy-3-methylbut-2-enyl diphosphate reductase, chloroplastic & 35.9 & 19 & 3.5 & $7.98 \times 10^{-4}$ \\
\hline 115437808 & Oxidoreductase-like & 24.3 & 8 & 2.3 & $3.35 \times 10^{-2}$ \\
\hline 115464965 & Hexokinase-5 & 24.1 & 10 & 2.2 & $2.59 \times 10^{-2}$ \\
\hline 115439869 & Hexokinase-6 & 27.1 & 14 & 2.1 & $1.22 \times 10^{-2}$ \\
\hline 115452337 & L-ascorbate peroxidase 1 , cytosolic & 49.2 & 29 & 0.4 & $9.02 \times 10^{-3}$ \\
\hline 115467370 & Putative pyrophosphate-dependent phosphofructokinase beta subunit & 31.2 & 17 & 0.4 & $9.90 \times 10^{-3}$ \\
\hline 115484175 & Pyruvate kinase & 31.3 & 23 & 0.3 & $2.35 \times 10^{-2}$ \\
\hline 115465974 & 6-phosphogluconate dehydrogenase, decarboxylating 1 & 44.8 & 29 & 0.3 & $6.70 \times 10^{-7}$ \\
\hline 115434198 & Fructose-bisphosphate aldolase & 24.5 & 10 & 0.3 & $1.53 \times 10^{-2}$ \\
\hline 115441963 & Putative transaldolase & 42.6 & 22 & 0.2 & $2.29 \times 10^{-3}$ \\
\hline \multirow[t]{2}{*}{115473973} & Xylose isomerase & 34.5 & 17 & 0.2 & $1.06 \times 10^{-5}$ \\
\hline & Disaccharide metabolism & & & & \\
\hline 115439937 & Putative trehalose-6-phosphate synthase/phosphatase & 5.0 & 5 & 4.1 & $2.00 \times 10^{-2}$ \\
\hline 115452927 & Sucrose synthase 4 & 9.4 & 9 & 0.5 & $1.24 \times 10^{-2}$ \\
\hline 115466896 & Sucrose synthase 2 & 36.1 & 32 & 0.4 & $1.10 \times 10^{-3}$ \\
\hline \multirow[t]{2}{*}{115453437} & Sucrose synthase 1 & 43.3 & 36 & 0.1 & $2.55 \times 10^{-5}$ \\
\hline & Polysaccharide metabolism & & & & \\
\hline 115471703 & Granule binding starch synthase ॥ & 22.2 & 14 & 25.6 & $7.88 \times 10^{-5}$ \\
\hline 115474235 & Putative uncharacterized protein P0034A04.101-1 & 26.4 & 30 & 17.4 & $5.07 \times 10^{-5}$ \\
\hline 115451283 & Inositol-3-phosphate synthase & 23.7 & 11 & 9.2 & $4.04 \times 10^{-5}$ \\
\hline 115476014 & $\begin{array}{l}\text { Glucose-1-phosphate adenylyltransferase small subunit, chloroplastic/ } \\
\text { amyloplastic }\end{array}$ & 36.1 & 23 & 6.4 & $7.94 \times 10^{-3}$ \\
\hline 115455167 & Glucose-1-phosphate adenylyltransferase & 42.7 & 30 & 4.4 & $4.71 \times 10^{-8}$ \\
\hline 115460666 & Soluble starch synthase III-1 & 11.5 & 16 & 3.8 & $3.09 \times 10^{-2}$ \\
\hline 115461086 & Probable UDP-arabinopyranose mutase 2 & 10.7 & 4 & 0.3 & $1.00 \times 10^{-2}$ \\
\hline 115470060 & 1,4-alpha-glucan-branching enzyme, chloroplastic/amyloplastic & 7.3 & 6 & 0.1 & $1.93 \times 10^{-3}$ \\
\hline 115454033 & UDP-arabinopyranose mutase 1 & 52.2 & 24 & 0.1 & $1.53 \times 10^{-6}$ \\
\hline 115459168 & Chitinase 4 & 11.8 & 3 & 0.1 & $1.53 \times 10^{-2}$ \\
\hline
\end{tabular}


Table 2 Differentially accumulated proteins between mock-inoculated leaves and RSV-infected leaves (Continued)

\begin{tabular}{|c|c|c|c|c|c|}
\hline & Fatty acid metabolism & & & & \\
\hline 115444801 & Lipoxygenase & 16.3 & 12 & 17.1 & $4.99 \times 10^{-6}$ \\
\hline 115489048 & Lipoxygenase & 17.6 & 15 & 7.0 & $7.04 \times 10^{-3}$ \\
\hline 115441871 & Acyl-[acyl-carrier-protein] desaturase 2, chloroplastic & 11.5 & 4 & 4.6 & $1.66 \times 10^{-2}$ \\
\hline 115436430 & Putative tetrafunctional protein of glyoxysomal fatty acid beta-oxidation & 17.3 & 13 & 0.3 & $2.76 \times 10^{-4}$ \\
\hline \multirow[t]{2}{*}{115445513} & Peroxisomal fatty acid beta-oxidation multifunctional protein & 21.9 & 18 & 0.1 & $7.07 \times 10^{-8}$ \\
\hline & Amino acid metabolism & & & & \\
\hline 115455221 & Serine hydroxymethyltransferase & 57.1 & 73 & 22.1 & $4.47 \times 10^{-12}$ \\
\hline 115461066 & Glutamine synthetase, chloroplastic & 61.0 & 69 & 20.1 & $5.47 \times 10^{-4}$ \\
\hline 115460656 & Aminomethyltransferase & 57.1 & 51 & 19.8 & $4.34 \times 10^{-5}$ \\
\hline 115442595 & Cysteine synthase & 51.3 & 60 & 14.6 & $1.19 \times 10^{-4}$ \\
\hline 115439533 & Glycine dehydrogenase P protein & 60.8 & 157 & 12.8 & $1.08 \times 10^{-4}$ \\
\hline 115457070 & Cysteine synthase & 43.0 & 18 & 9.7 & $3.31 \times 10^{-5}$ \\
\hline 115478398 & Aspartate kinase-homoserine dehydrogenase & 10.9 & 11 & 5.8 & $2.85 \times 10^{-3}$ \\
\hline 115476972 & Putative 3-deoxy-D-arabino-heptulosonate 7-phosphate synthase & 23.6 & 12 & 5.2 & $2.76 \times 10^{-4}$ \\
\hline 115433966 & Os01g0101200 protein & 19.0 & 10 & 3.1 & $2.48 \times 10^{-2}$ \\
\hline 115480417 & Putative dehydroquinate synthase & 37.9 & 20 & 2.8 & $7.39 \times 10^{-3}$ \\
\hline 115450561 & ATP phosphoribosyltransferase, chloroplastic & 22.8 & 10 & 2.7 & $1.57 \times 10^{-2}$ \\
\hline 115448201 & Carbamoyl-phosphate synthase small chain, chloroplastic & 20.7 & 9 & 2.7 & $4.08 \times 10^{-2}$ \\
\hline 115445929 & Probable diaminopimelate decarboxylase, chloroplastic & 30.4 & 14 & 2.5 & $2.14 \times 10^{-3}$ \\
\hline 115486343 & Phosphoserine phosphatase & 17.6 & 4 & 2.5 & $4.98 \times 10^{-2}$ \\
\hline 115468570 & Cysteine synthase & 11.2 & 5 & 2.3 & $4.85 \times 10^{-2}$ \\
\hline 115482324 & Glutamine synthetase family & 4.9 & 4 & 0.6 & $3.26 \times 10^{-2}$ \\
\hline 115461214 & Methylthioribose kinase 1 & 14.2 & 6 & 0.4 & $4.30 \times 10^{-2}$ \\
\hline 115449517 & Glutathione reductase, cytosolic & 20.8 & 9 & 0.4 & $2.44 \times 10^{-2}$ \\
\hline 115456165 & Probable methylenetetrahydrofolate reductase & 36.4 & 24 & 0.4 & $9.95 \times 10^{-6}$ \\
\hline 115466226 & 3-phosphoshikimate 1-carboxyvinyltransferase & 22.7 & 12 & 0.4 & $3.98 \times 10^{-2}$ \\
\hline 115434790 & Phospholipase D alpha 1 & 28.5 & 23 & 0.3 & $6.75 \times 10^{-4}$ \\
\hline 115454997 & Glutamate decarboxylase & 22.4 & 10 & 0.3 & $7.16 \times 10^{-3}$ \\
\hline \multirow[t]{2}{*}{115447403} & Phenylalanine ammonia-lyase & 45.6 & 36 & 0.1 & $2.39 \times 10^{-2}$ \\
\hline & Generation of precursor metabolites and energy & & & & \\
\hline 115472339 & Putative ATP synthase gamma chain 1 , chloroplast & 44.4 & 70 & 24.9 & $1.72 \times 10^{-9}$ \\
\hline 115472727 & Cytochrome b6-f complex iron-sulfur subunit, chloroplastic & 56.0 & 37 & 23.1 & $1.34 \times 10^{-4}$ \\
\hline 115457390 & ATP synthase B chain & 50.3 & 23 & 11.7 & $2.97 \times 10^{-3}$ \\
\hline 115435200 & Putative phosphoenolpyruvate carboxylase 1 & 29.0 & 34 & 7.4 & $1.51 \times 10^{-4}$ \\
\hline 115452259 & ATP synthase B chain, chloroplast & 34.6 & 30 & 5.8 & $8.67 \times 10^{-4}$ \\
\hline 115448701 & Putative $\mathrm{H}(+)$-transporting ATP synthase & 26.3 & 25 & 5.1 & $8.73 \times 10^{-4}$ \\
\hline 115469362 & Putative vacuolar proton-ATPase & 43.4 & 36 & 0.6 & $1.69 \times 10^{-2}$ \\
\hline 115435934 & NAD-dependent isocitrate dehydrogenase a & 29.3 & 11 & 0.6 & $3.96 \times 10^{-2}$ \\
\hline 115474559 & Succinate dehydrogenase [ubiquinone] iron-sulfur subunit, mitochondrial & 24.9 & 8 & 0.5 & $1.16 \times 10^{-2}$ \\
\hline 115438975 & Putative $\mathrm{H}+$-exporting ATPase & 40.0 & 11 & 0.5 & $6.50 \times 10^{-3}$ \\
\hline 115444791 & Citrate synthase & 26.9 & 13 & 0.4 & $2.19 \times 10^{-3}$ \\
\hline 115447367 & Succinyl-CoA ligase [ADP-forming] subunit beta, mitochondrial & 31.0 & 14 & 0.3 & $1.77 \times 10^{-2}$ \\
\hline 115470583 & Ferredoxin-NADP reductase, embryo isozyme, chloroplastic & 16.4 & 6 & 0.3 & $5.45 \times 10^{-3}$ \\
\hline 115470493 & Succinate dehydrogenase [ubiquinone] flavoprotein subunit, mitochondrial & 13.2 & 9 & 0.2 & $2.91 \times 10^{-3}$ \\
\hline
\end{tabular}


Table 2 Differentially accumulated proteins between mock-inoculated leaves and RSV-infected leaves (Continued)

\begin{tabular}{|c|c|c|c|c|c|}
\hline 115469332 & Glutaredoxin-C8 & 36.4 & 3 & 0.1 & $4.59 \times 10^{-2}$ \\
\hline 115459340 & Glutaredoxin-C6 & 43.8 & 7 & 0.1 & $9.69 \times 10^{-3}$ \\
\hline \multirow[t]{2}{*}{115470941} & Thioredoxin $\mathrm{H} 1$ & 40.2 & 11 & 0.1 & $7.29 \times 10^{-3}$ \\
\hline & Vitamin metabolism & & & & \\
\hline 115472485 & Thiamine thiazole synthase, chloroplastic & 49.8 & 29 & 6.7 & $5.04 \times 10^{-3}$ \\
\hline 115454593 & Thiamine biosynthesis protein thiC & 25.7 & 14 & 5.4 & $3.81 \times 10^{-7}$ \\
\hline 115446113 & Riboflavin biosynthesis protein RibD family protein & 9.2 & 4 & 3.9 & $1.81 \times 10^{-2}$ \\
\hline \multirow[t]{2}{*}{115482032} & GDP-mannose 3,5-epimerase 1 & 42.6 & 26 & 2.7 & $4.02 \times 10^{-2}$ \\
\hline & Nucleotide metabolism & & & & \\
\hline 115475007 & Putative uncharacterized protein OJ1590_E05.35-1 & 10.5 & 4 & 9.5 & $7.33 \times 10^{-3}$ \\
\hline 115455473 & WRKY DNA binding domain containing protein & 4.9 & 5 & 5.1 & $1.59 \times 10^{-2}$ \\
\hline 115450117 & (RAP Annotation release2) Formyltetrahydrofolate deformylase family protein & 13.2 & 4 & 4.2 & $1.28 \times 10^{-2}$ \\
\hline 115462253 & Probable GTP diphosphokinase CRSH2, chloroplastic & 15.7 & 9 & 3.8 & $4.78 \times 10^{-2}$ \\
\hline 115480339 & Deoxyribodipyrimidine photolyase family protein-like & 8.5 & 6 & 3.5 & $1.70 \times 10^{-2}$ \\
\hline 115488968 & Nucleoside diphosphate kinase & 31.8 & 11 & 3.3 & $9.20 \times 10^{-3}$ \\
\hline 115454773 & Adenylosuccinate synthetase 2 , chloroplastic & 34.0 & 21 & 3.1 & $8.43 \times 10^{-4}$ \\
\hline 115464251 & Putative uracil phosphoribosyltransferase & 28.9 & 9 & 3.0 & $7.42 \times 10^{-4}$ \\
\hline \multirow[t]{2}{*}{115451155} & SAP-like protein & 13.1 & 4 & 2.9 & $4.14 \times 10^{-2}$ \\
\hline & Isoprenoid metabolism & & & & \\
\hline 115472641 & Putative isopentenyl pyrophosphate:dimethyllallyl pyrophosphate isomerase & 12.6 & 3 & 15.6 & $7.33 \times 10^{-3}$ \\
\hline 115447171 & 4-Hydroxy-3-methylbut-2-en-1-yl diphosphate synthase, chloroplastic & 28.2 & 21 & 9.2 & $1.37 \times 10^{-8}$ \\
\hline 115471093 & Zeta-carotene desaturase & 26.8 & 18 & 7.9 & $4.21 \times 10^{-6}$ \\
\hline 115458652 & Zeaxanthin epoxidase, chloroplastic & 16.2 & 10 & 5.9 & $3.86 \times 10^{-5}$ \\
\hline 115434044 & 1-Deoxy-D-xylulose 5-phosphate reductoisomerase, chloroplastic & 24.7 & 15 & 4.5 & $3.59 \times 10^{-2}$ \\
\hline \multirow[t]{2}{*}{115451171} & Phytoene dehydrogenase, chloroplastic/chromoplastic & 15.4 & 9 & 2.8 & $2.84 \times 10^{-2}$ \\
\hline & Phosphorus metabolism & & & & \\
\hline 115463815 & Pyruvate, phosphate dikinase 1 , chloroplastic & 40.4 & 51 & 7.4 & $1.85 \times 10^{-11}$ \\
\hline 115448919 & Chloroplast inorganic pyrophosphatase & 42.2 & 19 & 6.3 & $2.57 \times 10^{-2}$ \\
\hline 115488252 & Phosphoglucan, water dikinase, chloroplastic & 12.9 & 15 & 3.8 & $2.37 \times 10^{-6}$ \\
\hline \multirow[t]{2}{*}{115468200} & Alpha-glucan water dikinase & 13.0 & 18 & 3.0 & $8.67 \times 10^{-5}$ \\
\hline & Sulfur metabolism & & & & \\
\hline 115456862 & ATP sulfurylase & 55.6 & 17 & 7.0 & $2.17 \times 10^{-3}$ \\
\hline 115472303 & Probable $5^{\prime}$-adenylylsulfate reductase 1 , chloroplastic & 20.6 & 11 & 3.9 & $5.43 \times 10^{-4}$ \\
\hline \multirow[t]{2}{*}{115450913} & Glutathione reductase, chloroplast & 31.0 & 20 & 3.3 & $1.25 \times 10^{-3}$ \\
\hline & Macromolecule catabolic process & & & & \\
\hline 115444937 & 265 proteasome regulatory particle triple-A ATPase subunit 6 & 30.9 & 16 & 0.4 & $3.81 \times 10^{-3}$ \\
\hline \multirow[t]{2}{*}{115466690} & Putative 265 proteasome regulatory particle triple-A ATPase subunit $5 a$ & 20.3 & 12 & 0.2 & $2.09 \times 10^{-3}$ \\
\hline & Response to reactive oxygen species & & & & \\
\hline 115446663 & Probable L-ascorbate peroxidase 8 , chloroplastic & 27.2 & 31 & 6.7 & $2.50 \times 10^{-2}$ \\
\hline 115450521 & Catalase & 47.2 & 38 & 6.2 & $1.09 \times 10^{-2}$ \\
\hline 115477837 & Superoxide dismutase [Cu-Zn], chloroplastic & 54.0 & 28 & 5.4 & $1.30 \times 10^{-2}$ \\
\hline 115473833 & Thioredoxin reductase NTRC & 33.0 & 12 & 4.4 & $1.38 \times 10^{-5}$ \\
\hline \multirow[t]{2}{*}{115477687} & L-Ascorbate peroxidase & 34.4 & 24 & 3.2 & $1.48 \times 10^{-2}$ \\
\hline & Cofactor metabolism & & & & \\
\hline 115479433 & Formate-tetrahydrofolate ligase & 29.4 & 25 & 3.0 & $4.12 \times 10^{-3}$ \\
\hline
\end{tabular}


Table 2 Differentially accumulated proteins between mock-inoculated leaves and RSV-infected leaves (Continued)

\begin{tabular}{|c|c|c|c|c|c|}
\hline 115440827 & ABC transporter subunit-like & 13.2 & 8 & 2.7 & $1.62 \times 10^{-2}$ \\
\hline \multirow[t]{2}{*}{115434288} & Putative SufD & 18.1 & 9 & 2.6 & $4.64 \times 10^{-2}$ \\
\hline & Regulation of nitrogen utilization & & & & \\
\hline 115477733 & Putative NADPH-dependent reductase & 41.2 & 18 & 7.4 & $2.14 \times 10^{-7}$ \\
\hline 115445203 & Putative UOS1 & 30.3 & 19 & 6.9 & $1.72 \times 10^{-6}$ \\
\hline 115469824 & Putative UOS1 & 23.3 & 13 & 5.5 & $6.31 \times 10^{-4}$ \\
\hline \multirow[t]{2}{*}{115453029} & Divinyl chlorophyllide a 8-vinyl-reductase, chloroplastic & 24.2 & 11 & 4.6 & $6.54 \times 10^{-3}$ \\
\hline & Cellular homeostasis & & & & \\
\hline 115472057 & Thioredoxin-like protein CDSP32, chloroplastic & 29.9 & 13 & 10.1 & $2.89 \times 10^{-5}$ \\
\hline 115444771 & Peroxiredoxin-2E-2, chloroplastic & 63.1 & 34 & 7.7 & $6.91 \times 10^{-5}$ \\
\hline 115466906 & Peroxiredoxin Q, chloroplastic & 45.2 & 22 & 7.6 & $5.32 \times 10^{-4}$ \\
\hline 115446541 & 2-Cys peroxiredoxin BAS1, chloroplastic & 56.3 & 36 & 5.2 & $3.44 \times 10^{-3}$ \\
\hline 115477793 & Putative auxin-regulated protein & 32.8 & 13 & 4.5 & $3.11 \times 10^{-2}$ \\
\hline 115436320 & Dihydrolipoyl dehydrogenase & 56.3 & 47 & 3.9 & $4.04 \times 10^{-5}$ \\
\hline 115435536 & Peptide transporter protein-like & 10.7 & 3 & 2.8 & $1.39 \times 10^{-2}$ \\
\hline 115471449 & Putative uncharacterized protein OJ1370_E02.126 & 39.3 & 10 & 1.8 & $2.24 \times 10^{-2}$ \\
\hline 115464793 & Thioredoxin & 14.9 & 3 & 0.5 & $3.06 \times 10^{-2}$ \\
\hline 115479475 & Protein disulfide isomerase-like $2-3$ & 15.7 & 5 & 0.3 & $2.01 \times 10^{-2}$ \\
\hline 115462193 & Protein disulfide isomerase-like 2-1 & 17.2 & 6 & 0.3 & $1.99 \times 10^{-3}$ \\
\hline 115455973 & Thioredoxin $\mathrm{H} 2-2$ & 14.2 & 2 & 0.2 & $3.38 \times 10^{-2}$ \\
\hline \multirow[t]{2}{*}{115484585} & Protein disulfide isomerase-like 1-1 & 28.1 & 20 & 0.1 & $9.78 \times 10^{-8}$ \\
\hline & Oxidation reduction & & & & \\
\hline 115484891 & Rieske [2Fe-2S] domain & 35.0 & 18 & 13.7 & $3.63 \times 10^{-5}$ \\
\hline 115459670 & $\mathrm{NAD}(\mathrm{P}) \mathrm{H}$-quinone oxidoreductase subunit $\mathrm{M}$, chloroplastic & 39.1 & 14 & 11.5 & $6.11 \times 10^{-3}$ \\
\hline 115481490 & Flavonoid 3'-hydroxylase & 6.1 & 3 & 7.8 & $3.64 \times 10^{-2}$ \\
\hline 115476190 & Putative oxidoreductase, zinc-binding & 51.0 & 34 & 6.6 & $3.97 \times 10^{-6}$ \\
\hline 115476820 & Nitrate reductase $[\mathrm{NADH}] 1$ & 6.3 & 5 & 6.0 & $1.29 \times 10^{-2}$ \\
\hline 115477461 & Moco containing protein & 34.5 & 13 & 5.1 & $1.02 \times 10^{-3}$ \\
\hline 115482950 & Aldo/keto reductase family protein & 9.3 & 3 & 5.1 & $2.94 \times 10^{-3}$ \\
\hline 115454109 & Oxidoreductase, aldo/keto reductase family protein & 38.5 & 16 & 4.9 & $2.69 \times 10^{-4}$ \\
\hline 115476618 & Glyceraldehyde-3-phosphate dehydrogenase & 36.5 & 29 & 4.7 & $8.09 \times 10^{-3}$ \\
\hline 115443657 & Putative ferredoxin-NADP(H) oxidoreductase & 55.1 & 51 & 4.3 & $2.52 \times 10^{-3}$ \\
\hline 115484125 & L-galactono-1,4-lactone dehydrogenase 1, mitochondrial & 6.7 & 3 & 3.9 & $1.56 \times 10^{-3}$ \\
\hline 115446723 & Glucose/ribitol dehydrogenase family protein & 19.1 & 4 & 2.6 & $1.50 \times 10^{-2}$ \\
\hline 115477843 & Putative malate dehydrogenase [NADP], chloroplast & 21.5 & 13 & 2.5 & $1.35 \times 10^{-2}$ \\
\hline 115438082 & Cytosolic aldehyde dehydrogenase & 21.5 & 11 & 2.1 & $4.10 \times 10^{-2}$ \\
\hline 115487892 & NADP-dependent oxidoreductase P2 & 17.9 & 6 & 1.8 & $2.31 \times 10^{-2}$ \\
\hline 115456131 & Putative alcohol dehydrogenase & 26.7 & 6 & 0.6 & $4.09 \times 10^{-2}$ \\
\hline 115443911 & NADPH-dependent mannose 6-phosphate reductase & 26.9 & 12 & 0.6 & $1.66 \times 10^{-2}$ \\
\hline 115482810 & Malic enzyme & 20.2 & 11 & 0.5 & $2.47 \times 10^{-3}$ \\
\hline 115460254 & OSJNBa0009P12.34 protein & 12.4 & 4 & 0.5 & $1.82 \times 10^{-2}$ \\
\hline 115478070 & Putative NADPH-dependent retinol dehydrogenase/reductase & 26.1 & 8 & 0.4 & $3.40 \times 10^{-2}$ \\
\hline 115484519 & Aldehyde dehydrogenase & 12.0 & 5 & 0.4 & $7.24 \times 10^{-3}$ \\
\hline 115479375 & Aldehyde dehydrogenase & 29.9 & 15 & 0.4 & $6.28 \times 10^{-3}$ \\
\hline 115463191 & Superoxide dismutase $[\mathrm{Mn}]$, mitochondrial & 32.9 & 13 & 0.3 & $3.01 \times 10^{-2}$ \\
\hline
\end{tabular}


Table 2 Differentially accumulated proteins between mock-inoculated leaves and RSV-infected leaves (Continued)

\begin{tabular}{|c|c|c|c|c|c|}
\hline 115464645 & Hypothetical protein & 5.7 & 3 & 0.3 & $3.11 \times 10^{-2}$ \\
\hline 115434810 & NADH-cytochrome b5 reductase & 22.8 & 7 & 0.3 & $2.15 \times 10^{-2}$ \\
\hline 115451245 & Oxidoreductase, zinc-binding dehydrogenase family protein & 16.1 & 5 & 0.3 & $1.48 \times 10^{-2}$ \\
\hline 115478148 & Isopenicillin N synthase family protein & 5.2 & 2 & 0.2 & $7.89 \times 10^{-3}$ \\
\hline \multirow[t]{2}{*}{115462115} & Putative 1-aminocyclopropane-1-carboxylate oxidase & 11.0 & 3 & 0.2 & $1.34 \times 10^{-2}$ \\
\hline & Response to oxidative stress & & & & \\
\hline 115445243 & Class III peroxidase 29 & 38.9 & 20 & 39.8 & $3.19 \times 10^{-3}$ \\
\hline 115460338 & Haem peroxidase family protein & 32.9 & 20 & 4.5 & $4.36 \times 10^{-5}$ \\
\hline 115436084 & Class III peroxidase 11 & 26.2 & 8 & 4.4 & $2.78 \times 10^{-2}$ \\
\hline 115474059 & Peroxidase & 47.0 & 19 & 0.3 & $1.30 \times 10^{-2}$ \\
\hline 115436300 & Class III peroxidase 16 & 23.1 & 10 & 0.3 & $2.50 \times 10^{-2}$ \\
\hline 115456523 & Salt tolerance protein & 27.5 & 7 & 0.2 & $5.25 \times 10^{-4}$ \\
\hline 115459848 & Glutathione peroxidase & 33.9 & 10 & 0.2 & $4.64 \times 10^{-2}$ \\
\hline \multirow[t]{2}{*}{115442403} & Putative peroxidase & 37.9 & 19 & 0.1 & $3.85 \times 10^{-4}$ \\
\hline & Others & & & & \\
\hline 115450080 & Cell division inhibitor-like & 20.9 & 14 & 5.4 & $2.53 \times 10^{-2}$ \\
\hline 115450329 & Peroxisomal membrane protein 11-1 & 21.9 & 5 & 4.8 & $2.94 \times 10^{-2}$ \\
\hline 115452321 & Ribosomal protein L10 containing protein & 50.9 & 15 & 4.1 & $3.30 \times 10^{-4}$ \\
\hline 115439157 & Two pore calcium channel protein 1 & 2.0 & 1 & 3.8 & $3.56 \times 10^{-2}$ \\
\hline 115457630 & Phototropin-2 & 17.0 & 12 & 2.9 & $1.21 \times 10^{-4}$ \\
\hline 115474273 & Phosphoinositide phospholipase C & 27.3 & 15 & 0.5 & $4.60 \times 10^{-2}$ \\
\hline 115446411 & RNA binding protein Rp120 & 29.6 & 29 & 0.5 & $1.61 \times 10^{-2}$ \\
\hline 115448225 & GTPase activating protein-like & 5.2 & 4 & 0.3 & $5.92 \times 10^{-3}$ \\
\hline 115453079 & Villin-3 & 20.7 & 17 & 0.3 & $5.15 \times 10^{-3}$ \\
\hline 115451401 & Mitochondrial outer membrane protein porin 5 & 49.1 & 21 & 0.3 & $4.79 \times 10^{-3}$ \\
\hline 115441759 & Dolichyl-diphosphooligosaccharide-protein glycosyltransferase subunit 2 & 10.3 & 6 & 0.3 & $1.12 \times 10^{-4}$ \\
\hline 297601526 & Probable linoleate 9S-lipoxygenase 4 & 22.4 & 15 & 0.2 & $2.78 \times 10^{-3}$ \\
\hline 115434036 & Putative isoflavone reductase & 19.8 & 5 & 0.2 & $1.38 \times 10^{-2}$ \\
\hline 115486998 & Non-specific lipid-transfer protein 2B & 57.3 & 17 & 0.1 & $4.26 \times 10^{-3}$ \\
\hline 115444635 & Response regulator & 2.1 & 3 & 0.02 & $2.08 \times 10^{-2}$ \\
\hline
\end{tabular}

Note: "Peptides $(95 \%)$ " indicates distinct peptides were identified with at least $95 \%$ confidence (protein score cutoff $>1.5$ ); "Cov (95)" means percentage of matching amino acids from identified peptides with confidence over $95 \%$; Ratio and $P$-value represents tag labeled for mock leaves: tag labeled for RSV-infected leaves. Ratio $>1.5$ is considered as downregulated and $<0.67$ is upregulated

results demonstrated that expression of the genes for CHLI and CHLD (magnesium chelatase) in RSV-infected leaves was downregulated more than three times the level of the control (Fig. 6a), and transcription of genes encoding radc1, rap and p0026h03.19 in RSV-infected leaves were upregulated 14, 2, 3 times higher than the level of the control leaves, respectively (Fig. 6a), verifying the iTRAQ results. Similarly, this trend for mRNA levels of the genes for CHLI and p0026h03.19 by Northern blotting analyses also supported the transcription of genes encoding respective protein by RT-qPCR (Fig. 6b). Whereas, elevated levels of five genes were different between transcription and proteins levels that may be due to posttranscription and posttranslational regulatory processes.

\section{Discussion}

In the present study, iTRAQ-based experiments were implemented to identify proteins that were differentially accumulated between the RSV-infected and mockinoculated leaves, then to determine which proteins may be involved in symptom formation. During RSV infection, 681 differentially accumulated proteins were found (Fig. 2; Table 1); 492 of these proteins were annotated by GO and located mostly in plastids, including the chloroplast, and participating in chlorophyll metabolism (Fig. 3, 4; Table 2). Chloroplast proteins was degraded by chloroplast vesiculation [41]. Upon RSV infection, the chloroplast vesiculation possibly targeted and destabilized the chloroplast for protein degradation, which resulted in cell death and 


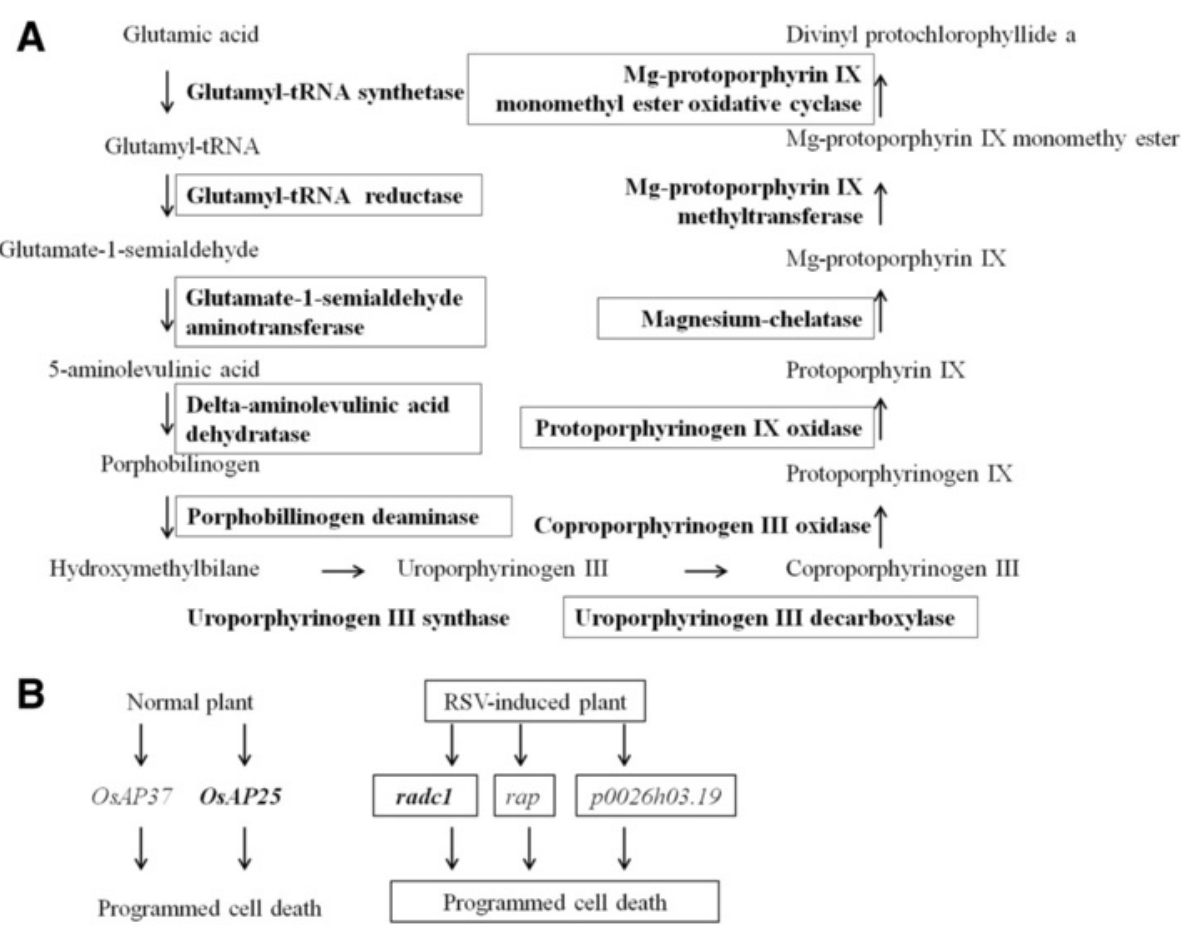

Fig. 5 a Enzymes of chlorophyll biosynthetic pathway that decreased in accumulation during RSV infection. Selected steps are from KEGG pathways map (map 00860) for metabolism and enzymes. Bold words represent enzymes: glutamyl-tRNA synthetase, uroporphyrinogen III synthase, Mg-protoporphyrin IX methyltransferase, coproporphyrinogen III oxidase; boxed words represent enzymes: glutamyl-tRNA reductase, glutamate-1-semialdehyde aminotransferase, delta-aminolevulinic acid dehydratase, porphobillinogen deaminase, Mg-protoporphyrin IX monomethyl ester oxidative cyclase, magnesium-chelatase, protoporphyrinogen IX oxidase, uroporphyrinogen III decarboxylase. Eight enzymes at first stage of chlorophyll biosynthetic process were found and comprised 10 differentially accumulated proteins that were identified in RSV-induced leaves compared with the mock control leaves. $\mathbf{b}$ Two pathways could lead to programmed cell death including normal and RSV-induced plant. OsAP25 (radc1, Os03g0186900), OsAP37, rap, and p0026h03.19 were aspartic proteases genes

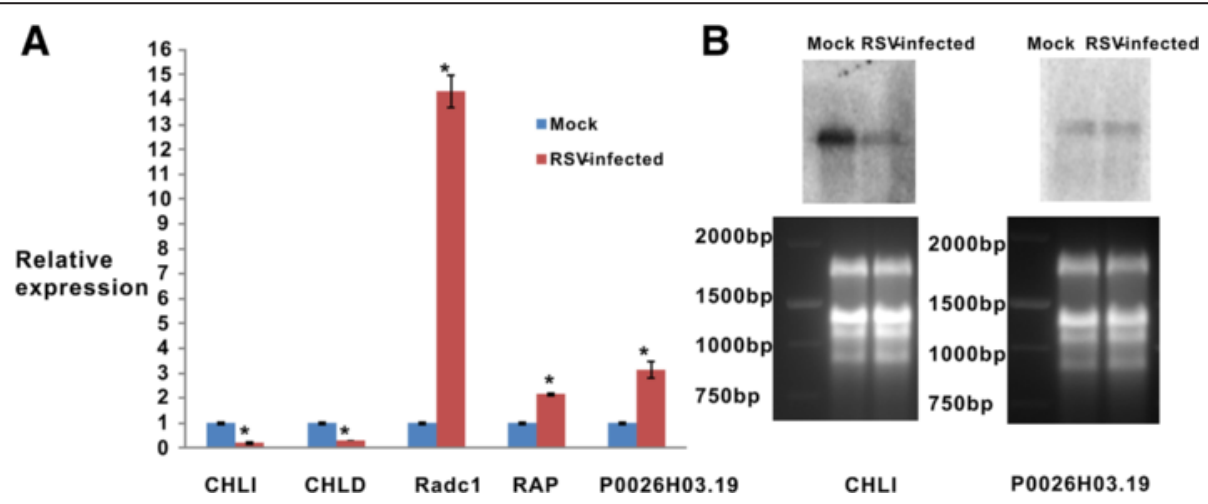

Fig. 6 Validation of rice gene expression levels by real time RT-PCR and Northern blotting. a Comparison of protein and mRNA expression levels of mock leaves and RSV-infected leaves using RT-qPCR. Blue represents mock leaves; red represents RSV-infected leaves. The averaged readings from the three biological replicates normalized against endogenous gene OsEF1a; error bar denoted SD. Statistics were analyzed using the Student's $t$-test. An asterisk indicated a significant difference from the corresponding control $(P<0.01)$. $\mathbf{b}$ Northern blot of two differentially expressed genes selected for verifying RT-qPCR results. Mock, mock-inoculated leaves; RSV-infected, RSV-infected leaves. Equal loading of total RNA was assessed by staining rRNA with ethidium bromide. Marker contained 2000 bp, 1500 bp, 1000 bp and 750 bp 
induced the formation of vesicle containing many plastid proteins. According to the String database, proteinprotein interaction networks were clustered in the chloroplast, defensive and metabolism groups (Additional file 2: Figure S1). Based on the functional analysis and RSVinduced disease symptoms, several proteins were associated with leaf chlorosis, cell death and plant defense during RSV invasion (Fig. 1, 3, 4). Additionally, the transcription of genes encoding selected proteins using RT-qPCR and Northern blot analyses matched with iTRAQ results (Fig. 6). We will discuss these various changes in proteins with regard to their significance to disease symptoms.

\section{RSV induced a decrease in chlorophyll}

At $21 \mathrm{dpi}$, chlorotic stripes on newly emerged leaves are typical on rice plants infected by RSV (Fig. 1). Chlorosis is correlated with a reduction in chlorophyll during infection with a virus [11]. Recently, chlorophyll structure was also confirmed to be altered by accumulation of RSV SP, and PsbP (oxygen-evolving complex protein) was shown to participate in the interaction between rice and RSV [16]. Similarly, we used iTRAQ to determine that the accumulation of four oxygen-evolving enhancer proteins in RSV-induced leaves was lower than in the control plants (Table 2); thus, reduced accumulation of oxygen-evolving enhancer protein is involved in interrupting chlorophyll production.

Chlorophyll production is also influenced independently by chlorophyll anabolic and catabolic reactions [42]. Here, eight enzymes involved in early steps of chlorophyll biosynthesis were identified as being lower in RSV-infected leaves than in the mock-inoculated leaves (Fig. 5a; Table 2), again implicating RSV infection in significantly inhibiting chlorophyll biosynthesis. One of these eight, magnesium chelatase, comprising three subunits (CHLI, CHLD, CHLH), is an important synthetic enzyme for chlorophyll $a$ and chlorophyll $b$ [43]. Specifically, subunits CHLI and CHLD were downregulated in RSV-infected leaves (Table 2, Fig. 3a) and had decreased mRNA levels (Fig. 6) compared with the control. These subunits are AAA+ proteins (ATPases associated with various cellular activities) and form a motor unit, which provides a structure for the functioning of magnesium chelatase [44, 45]. The reduced accumulation of CHLI and CHLD thus indicates that the function of magnesium chelatase in chlorophyll biosynthesis is also limited. These results suggest that the reduction of chlorophyll is associated with downregulation of magnesium chelatase during infection with RSV. Previous studies of CMV have shown that the yellow mosaic symptoms are induced by a domain of satellite RNA [46, 47]. Recently, small interfering RNA (siRNA) derived from this domain of satellite RNA was shown to mediate RNA silencing of the chlorophyll biosynthetic gene CHLI (magnesium protoporphyrin cheltase subunit I) and that CHLI mRNA is downregulated in the infected tobacco $[12,13]$. The yellowing domain of CMV satellite RNA induces RNA silencing of chlorophyll biosynthetic gene by small interfering RNA [12, 13]. Unlike CMV, RSV does not have satellite RNA; so how does RSV regulate and alter the chlorophyll biosynthetic pathway and induce chlorosis? In addition, a reduction of chlorophyll a/b-binding protein was shown to cause a downregulation of chlorophyll accumulation [14]. Here, the level of five chlorophyll a/b-binding proteins was reduced during RSV infection (Table 2). Therefore, RSV infection disrupts chlorophyll biosynthesis.

\section{Proteases coincided with cell death}

The ubiquitin-26S proteasome system targets intercellular regulators that have a central role in battling pathogens [48-51] and in leaf senescence [52]. Several of the $26 \mathrm{~S}$ proteasome units rose in accumulation in RSVinfected leaves compared with mock leaves (Table 2), suggesting it might promote host defense, then induce cell death in rice to restrict pathogen spread.

At the end stage of RSV infection, rice leaves developed chlorotic stripes, then the whole leaf died (Fig. 1b). Cell death requires a series of appropriate proteases. For example, over-expression of OsAP25 (Os03g0186900) and OsAP37 encoding aspartic proteases induces programmed cell death [18]. Similarly, in this study aspartic proteases encoded by radc1 (Os03g0186900), rap, and p0026h03.19 in RSV-infected leaves were sharply upregulated compared with the control leaves (Figs. 4 and 5b), indicating that the expression of the genes encoding aspartic protease was induced by RSV infection and participated in programmed cell death. However, we found that the aspartic protease pathway in RSV-infected leaves contained three proteins (radc1, rap, and p0026h03.19) that differed from the aspartic proteases (OsAP25 and OsAP37) in the normal plant. The aspartic protease pathway induced by a pathogen might thus be a new biological process.

\section{Defense reaction during RSV infection}

Pathogenesis-related protein is associated with systemic acquired resistance of plant against diverse pathogens [53]. RSV infection induced a plant defense response, as noted by the upregulation of the expression of the genes encoding rice pathogenesis-related proteins. Bet v1 allergen, a member of the ubiquitous family of pathogenesisrelated plant proteins, acts as a plant steroid carrier and has ribonuclease activity, suggesting it might play a key role in the plant defense response against pathogens [54-56]. In RSV-infected leaves, three pathogenesisrelated proteins belonging to the Bet $\mathrm{v} 1$ allergen family of proteins (OSJNBb0048E02.12) accumulated at a higher level than in mock leaves (Table 2). So the 
upregulation of Bet v1 allergen family proteins might improve the transport of a steroid such as a brassinosteroid and enhance ribonuclease activities against virus infection. In addition, the heat-shock protein HSP70 was more abundant in the RSV-infected leaves than in mock leaves (Table 2); thus RSV can induce HSP70 accumulation, as can various other RNA and DNA viruses [39, 40]. The expression of the genes encoding superoxide dismutase $[\mathrm{Mn}]$, superoxide dismutase $[\mathrm{Cu}-\mathrm{Zn}]$ and peroxidase was also altered in response to RSV invasion (Table 2). Superoxide dismutase and peroxidase in plant were also identified as upregulated in response to TMV infection [57]. However, superoxide dismutase $[\mathrm{Cu}-\mathrm{Zn}]$ was identified as downregulated during Sugarcane mosaic virus infection, showing that the regulation of superoxide dismutase can differ depending on the virus [58]. RSV infection thus clearly activated the accumulation of rice defense-related proteins, similar to the defense-related proteins such as PR10, HSP70 and peroxidase induced in rice infected by Rice yellow mottle virus (RYMV) that were identified using the 2-D method [59].

\section{Conclusions}

In summary, comparative proteomics analysis using iTRAQ LC-MS/MS technology identified 448 downregulated proteins and 233 upregulated proteins in many metabolic pathways during RSV infection. Several pathways potentially involved in RSV-induced symptom were found, including chlorophyll biosynthesis, proteolysis and defense response. Although our investigation provides knowledge of key proteins associated with the RSV-induced symptom, gene function analysis is needed to further understand the roles of these proteins in symptom formation. Therefore, our findings may provide new clues for elucidating the molecular mechanisms underlying RSV-induced symptom formation.

\section{Methods}

Insect population, plant materials and inoculation

A SBPH (small brown planthopper) population was maintained on susceptible rice (Oryza sativa var. japonica) cultivar (cv.) Wuyujing 3 in a climate chamber at $26{ }^{\circ} \mathrm{C}$ and a photoperiod of $14 \mathrm{~h}$ light and $10 \mathrm{~h}$ dark [60]. Third instar SBPH nymphs were allowed to feed on RSV-infected rice plants for a 3-day acquisition access period (AAP), then maintained in the climate chamber through the 10-day latent period. Ten viruliferous SBPH were then allowed to feed for a 2-day inoculation access period on three-leaved seedlings of Oryza sativa cv. Aichiasahi that had been grown in plastic pots containing a greenhouse soil mixture (40\% soil, $30 \%$ vermiculite, $30 \%$ straw powder). Subsequently, seedlings infested with non-viruliferous SBPH were used in the same way as a mock control. After the inoculation access period, seedlings were sprayed with insecticide and were transferred to insect-free greenhouse at $28^{\circ} \mathrm{C}$ to observe symptom formation daily.

\section{Sampling and RT-PCR (reverse transcription-polymerase chain reaction)}

Samples were collected from both RSV-infected leaves and mock leaves at $21 \mathrm{dpi}$ and immediately immersed in liquid nitrogen. Total RNA was extracted using Trizol reagent (Invitrogen Trading, Shanghai, China). M-MLV reverse transcriptase (Promega, Madison, USA) was used to reverse-transcribe $2 \mu \mathrm{g}$ of the total RNA with gene-specific primers (Additional file 1: Table S1). PCR was performed in a final volume of $50 \mu \mathrm{L}$ at $95{ }^{\circ} \mathrm{C}$ for $5 \mathrm{~min}, 32$ cycles of $95{ }^{\circ} \mathrm{C}$ for $30 \mathrm{~s}, 57{ }^{\circ} \mathrm{C}$ for $45 \mathrm{~s}, 72{ }^{\circ} \mathrm{C}$ for $50 \mathrm{~s}$. Amplified products were fractionated in a $1 \%$ agarose gel.

\section{Protein extraction, digestion and ITRAQ labeling}

To extract total proteins from the RSV-infected leaves and control leaves, the samples were homogenized in lysis buffer (7 M urea, $2 \mathrm{M}$ thiourea, $0.1 \%$ CHAPS), and the mixture was then incubated at $30{ }^{\circ} \mathrm{C}$ for $30 \mathrm{~min}$, and centrifuged at $15,000 \times g$ for $20 \mathrm{~min}$ at $4{ }^{\circ} \mathrm{C}$. The supernatant was collected and the proteins concentration was determined by the Bradford protein assay (Bio-Rad Laboratory, Hercules, CA, USA). Bovine serum albumin (BSA) was performed as the standard for the calibration curve. Approximately $200 \mu \mathrm{g}$ proteins were reduced with $1 \mathrm{M}$ dithiothreitol, alkylated with $1 \mathrm{M}$ iodoacetamide, dissolved in the dissolution buffer, and digested with trypsin (AB Sciex, Foster City, USA) at 1:50 (w/w) for $37^{\circ} \mathrm{C}$ overnight, which were then labeled using the iTRAQ Reagents 4-plex kit (AB Sciex) according to the manufacturer's instructions. The peptides from RSV-infected leaves and mock leaves were labeled with 117 and 116 tags, respectively (Fig. 7).

\section{Fractionation by reversed-phase high-performance liquid chromatography (HPLC)}

Using the RIGOL L-3000 HPLC Pump system, the iTRAQ-labeled samples were reconstituted with mobile phase A $\left(98 \% \mathrm{H}_{2} \mathrm{O}, 2 \%\right.$ acetonitrile, $\mathrm{pH} 10$ adjusted by ammonia water) and mobile phase B (98\% acetonitrile, $2 \% \mathrm{H}_{2} \mathrm{O}$ adjusted by ammonia water), then fractionated on a Durashell-C18 column $(4.6 \mathrm{~mm} \times 250 \mathrm{~mm}, 5 \mu \mathrm{m}$, $100 \AA$ A ; Agela, USA) at a speed of $0.7 \mathrm{~mL} \mathrm{~min}^{-1}$ using the gradient 0-5 min, 5-8 \% buffer B; 5-35 min, 8-18 \% buffer B; 35-62 min, 18-32\% buffer B; 62-64 min, 32-95\% buffer B; 64-68 min, $95 \%$ buffer B; 68-72 min, 95-5\% buffer B. The chromatograms were recorded at $214 \mathrm{~nm}$.

\section{Mass spectrometric (MS) analysis}

The fractionated peptides, dissolved in $2 \%$ methyl alcohol and $0.1 \%$ formic acid were analyzed using an ABI5600 system (Applied Biosystems). After equilibration of 


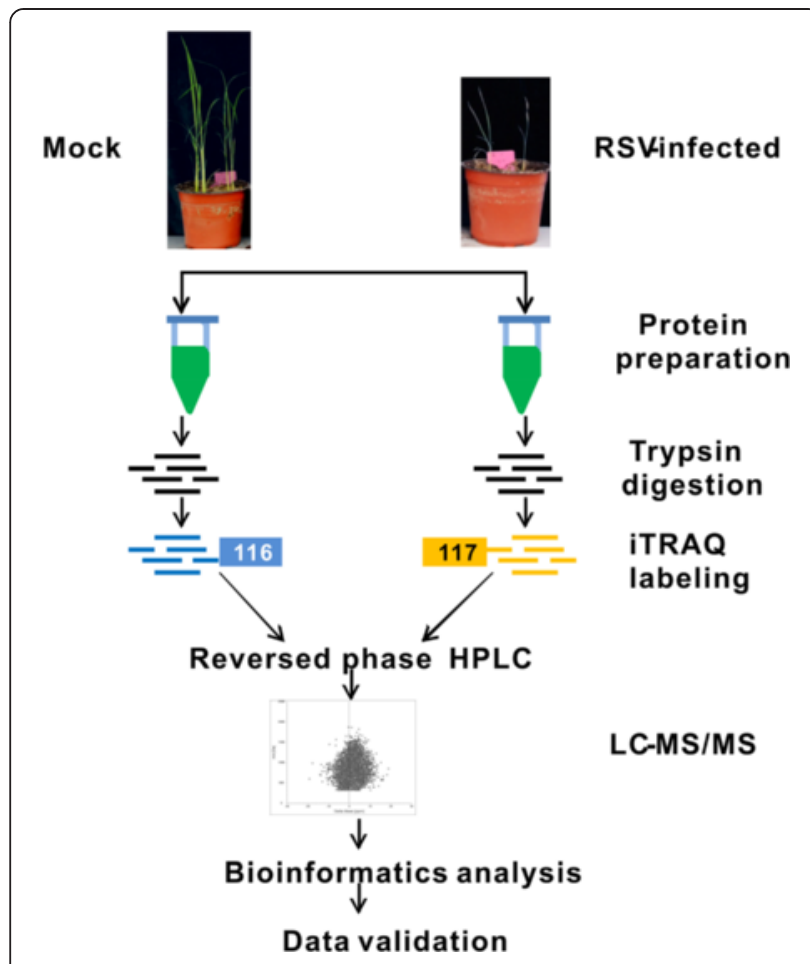

Fig. 7 Strategy for iTRAQ LC-MS/MS analysis of comparative proteomics in rice infected with Rice stripe virus (RSV). At 21 days after inoculation, mock leaves (inoculated with healthy small brown planthoppers [SBPH]) and RSV-inoculated leaves (inoculated via RSV-viruliferous SBPH) were collected to extract total proteins. After prepared proteins were digested with trypsin, the peptides were labeled with the ITRAQ reagent and pooled. Pooled peptides were fractioned using the reversed-phase HPLC system, then individual fractions were analyzed using LC-MS/MS. MS raw data were processed using the NCBI protein database. Identified proteins were then analyzed using the DAVID platform and STRING software. Finally, key proteins were selected to validate their expression

the column with solvent A $\left(100 \% \mathrm{H}_{2} \mathrm{O}, 0.1 \%\right.$ formic acid), the peptides eluted from the column (EASY-Spray column, $12 \mathrm{~cm} \times 75 \mu \mathrm{m}, \mathrm{C} 18,3 \mu \mathrm{m}$ ) with a 90-min mobile phase gradient using solvent B (100\% acetonitrile, $0.1 \%$ formic acid) with a flow rate of $350 \mathrm{~nL} \mathrm{~min}{ }^{-1}$, a spray voltage of $2.1 \mathrm{kV}$ and ionization interface temperature of $250{ }^{\circ} \mathrm{C}$. Scan range was from 350 to $1800 \mathrm{~m} / \mathrm{z}$. The charge states of peptides were set to +2 to +4 .

\section{Protein identification and quantification}

Proteins were identified and quantified by Protein Pilot Software 4.0 using the NCBI rice protein database (http:// www.ncbi.nlm.nih.gov/protein/?term=oryza+sativa) search algorithm (Applied Biosystems). Proteins were identified based on various parameters such as trypsin digestion; dynamic modification; false discovery rate (FDR) determination for all peptide and protein identifications $<1 \%$; precursor ion mass tolerance, $\pm 15 \mathrm{ppm}$; fragment ion mass tolerance, $\pm 20 \mathrm{mmu}$; max missed cleavages, 2 .
Proteins were quantified as a change in relative expression; proteins with a fold-change $>1.5(P<0.05)$ were considered to have decreased in level and those with fold-change $<0.67(P<0.05)$ as increased.

\section{Bioinformatics analysis}

The Gene Ontology (GO) annotation for functional analysis was done using the DAVID resources 6.7 (http:// david.abcc.ncifcrf.gov/) [61], and proteins were classified based on the molecular function, biological process, and cellular components. The Kyoto Encyclopedia of Genes and Genomes (KEGG) (http://www.kegg.jp/) annotation was also done for a pathway analysis [62], and we assessed the interaction network for differentially accumulated proteins using STRING software (http://string-db.org/) [63].

\section{Analysis of gene expression by RT-qPCR (reverse transcription quantitative polymerase chain reaction)} RT-qPCR primers were designed by Primer Premier Version 5.0 based on the ORF (open reading frame) sequence of candidate genes cloned from rice (Additional file 1: Table $\mathrm{S} 1$ ), and a primer set for endogenous gene OsEF1 $\alpha$ designed for another study [64] was also used. About $2 \mu \mathrm{g}$ total RNA was reverse-transcribed using the FastQuant RT kit (Tiangen Biotech-Beijing Co.) according to the manufacturer's instructions and then its concentration was measured by NanaDrop-1000 [65]. The RT-qPCR was done in final volume of $20 \mu \mathrm{L}$ using the SupperReal PreMix Plus (SYBR Green) kit and the manufacturer's instructions (Tiangen Biotech-Beijing Co.) in a ABI 7500 Real Time PCR thermal cycler and the following conditions: $95{ }^{\circ} \mathrm{C}$ for $15 \mathrm{~min}$; 40 cycles of $95{ }^{\circ} \mathrm{C}$ for $10 \mathrm{~s}, 55{ }^{\circ} \mathrm{C}$ for $32 \mathrm{~s}$, and $72{ }^{\circ} \mathrm{C}$ for $32 \mathrm{~s}$. The experiment was repeated three times. Data for the melt curve were collected at $95{ }^{\circ} \mathrm{C}$ for $15 \mathrm{~s}, 60{ }^{\circ} \mathrm{C}$ for $1 \mathrm{~min}, 95{ }^{\circ} \mathrm{C}$ for $30 \mathrm{~s}$, and $60^{\circ} \mathrm{C}$ for $15 \mathrm{~s}$. Relative gene expression was calculated by the $2^{-\Delta \Delta C T}$ method [66].

\section{Northern blot analysis}

Fifteen micrograms of the total RNA extracted was electrophoresed in a $1.5 \%$ formaldehyde agarose gel and transferred to a Hybond- $\mathrm{N}^{+}$membrane (GE Healthcare Bio-Scienes Corp., USA) [67]. The membrane was then baked at $80{ }^{\circ} \mathrm{C}$ for $2 \mathrm{~h}$, then probed with $\alpha-{ }^{32} \mathrm{P}$-dCTP- randomly primer labeled probe at $65{ }^{\circ} \mathrm{C}$ overnight in a perfect hyb $\mathrm{b}^{\mathrm{Tm}}$ plus hybridization buffer (Sigma-Aldrich, St. Louis, USA). After the hybridization, the membrane was washed twice with $2 \times$ SSC (sodium chloride-sodium citrate), $1 \times$ SDS (sodium dodecyl sulfate); $1 \times$ SSC, $1 \times$ SDS and $0.5 \times$ SSC, $0.5 \times$ SDS at $65{ }^{\circ} \mathrm{C}$, and the radioactive signals were detected using phosphor imaging. 


\section{Additional files}

Additional file 1: Table S1. The Gene Ontology (GO) annotation of differentially accumulated proteins using iTRAQ technology. Ratio represents tag labeled for mock leaves: tag labeled for RSV-infected leaves. Ratio $>1.5$ is considered as downregulated and $<0.67$ is upregulated.

Additional file 2: Figure S1. The interaction network of differentially accumulated proteins between mock leaves and RSV-infected leaves using STRING soft program. We submitted 681 identified proteins to the STRING and analyzed 547 proteins in interaction with each other and constructing the network (A), which were roughly divided into three parts: metabolism (B), chloroplast (C) and defense (D).

\section{Competing interests}

The authors declare that they have no competing interests.

\section{Authors' contributions}

BW contributed to the design of the study, iTRAQ-based quantitative proteomics analysis, designing the RT-qPCR protocol, statistical analysis and drafting the manuscript. JH contributed to sample collection, the RNA extractions, Northern blot analysis and drafting the manuscript. YR contributed to the design of the study, sample collection and drafting the manuscript. CL contributed to the design of the study and statistical analysis. XW contributed to the design of the study, statistical analysis and drafting the manuscript. All authors read and approved the final manuscript.

\section{Acknowledgments}

Financial support was provided by the National Key Basic Research of China (2010CB126203), the Special Fund for Agro-scientific Research in the Public Interest (201303021), and the Plan for Scientific Innovation Talent of Henan Province (144100510018).

\section{Author details}

${ }^{1}$ State Key Laboratory for Biology of Plant Diseases and Insect Pests, Institute of Plant Protection, Chinese Academy of Agricultural Sciences, 100193, Beijing, China. ${ }^{2}$ Institute of Plant Protection, Henan Academy of Agricultural Sciences, 450002 Zhengzhou, China.

\section{Received: 1 May 2015 Accepted: 18 June 2015}

\section{Published online: 26 June 2015}

\section{References}

1. Hibino H. Biology and epidemiology of rice viruses. Annu Rev Phytopathol. 1996;34:249-74.

2. Zhu FM, Xiao QP, Wang FM, Chen YL. Several new diseases occurring in rice south of the Yangtze River. Plant Protection. 1964;2:100-2.

3. Zhou Y, Li S, Cheng Z, Zhou T, Fan Y. Research advances in rice stripe disease in China. Jiangsu J Agr Sci. 2012;28:1007-15.

4. Zhang HM, Sun HR, Wang HD, Chen JP. Advances in the studies of molecular biology of Rice stripe virus. Acta Phytophyilacica Sinica. 2007;34:436-40.

5. Toriyama S. Rice stripe virus: prototype of a new group of viruses that replicate in plants and insects. Microbiol Sci. 1986;3:347-51.

6. Huo Y, Liu W, Zhang F, Chen X, Li L, Liu Q, et al. Transovarial transmission of a plant virus is mediated by vitellogenin of its insect vector. PLoS Path. 2014;10:e1003949.

7. Zhu Y, Hayakawa T, Toriyama S, Takahashi M. Complete nucleotide sequence of RNA 3 of rice stripe virus: an ambisense coding strategy. J Gen Virol. 1991;72:763-7.

8. Zhu Y, Hayakawa T, Toriyama S. Complete nucleotide sequence of RNA 4 of rice stripe virus isolate $T$, and comparison with another isolate and with maize stripe virus. J Gen Virol. 1992;73:1309-12.

9. Knudson LL, Tibbitts TW, Edwards GE. Measurement of ozone injury by determination of leaf chlorophyll concentration. Plant Physiol. 1977;60:606-8.

10. McNulty IB, Newman DW. Mechanism (s) of fluoride induced chlorosis. Plant Physiol. 1961:36:385-8.

11. Dawson WO. Tobamovirus-plant interactions. Virology. 1992;186:359-67.

12. Smith NA, Eamens AL, Wang M-B. Viral small interfering RNAs target host genes to mediate disease symptoms in plants. PLoS Path. 2011;7:e1002022.
13. Shimura H, Pantaleo V, Ishihara T, Myojo N, Inaba J-i, Sueda K, et al. A viral satellite RNA induces yellow symptoms on tobacco by targeting a gene involved in chlorophyll biosynthesis using the RNA silencing machinery. PLoS Path. 2011:7:e1002021.

14. Liu J, Yang J, Bi H, Zhang P. Why mosaic? Gene expression profiling of African cassava mosaic virus-infected cassava reveals the effect of chlorophyll degradation on symptom development. J Integr Plant Biol. 2014:56:122-32.

15. Lehto K, Tikkanen M, Hiriart JB, Paakkarinen V, Aro EM. Depletion of the photosystem II core complex in mature tobacco leaves infected by the flavum strain of tobacco mosaic virus. Mol Plant Microbe In. 2003;16:1135-44.

16. Kong $L, W u J, L u L, X u Y, Z$ hou $X$. Interaction between Rice stripe virus disease-specific protein and host PsbP enhances virus symptoms. Mol Plant. 2014;7:691-708.

17. Hatsugai N, Kuroyanagi M, Yamada K, Meshi T, Tsuda S, Kondo M, et al. A plant vacuolar protease, VPE, mediates virus-induced hypersensitive cell death. Science. 2004;305:855-8.

18. Niu NN, Liang WQ, Yang XJ, Jin WL, Wilson ZA, Hu JP, et al. EAT1 promotes tapetal cell death by regulating aspartic proteases during male reproductive development in rice. Nat Commun. 2013:4:1445.

19. Mar T, Liu WW, Wang XF. Proteomic analysis of interaction between P7-1 of Southern rice black-streaked dwarf virus and the insect vector reveals diverse insect proteins involved in successful transmission. J Proteomics. 2014;102:83-97.

20. Qin FL, Liu WW, Li L, Wang XF. Screening of putative proteins in vector Laodelphax striatellus which are interacted with disease-specific protein of Rice stripe virus by yeast two-hybrid based on the split-ubiquitin. Scientia Agricultura Sinica. 2014;47:2784-94.

21. Scofield SR, Tobias CM, Rathjen JP, Chang JH, Lavelle DT, Michelmore RW, et al. Molecular basis of gene-for-gene specificity in bacterial speck disease of tomato. Science. 1996;274:2063-5.

22. Nomura K, Debroy S, Lee YH, Pumplin N, Jones J, He SY. A bacterial virulence protein suppresses host innate immunity to cause plant disease. Science. 2006;313:220-3.

23. Feng F, Yang F, Rong W, Wu X, Zhang J, Chen S, et al. A Xanthomonas uridine 5 '-monophosphate transferase inhibits plant immune kinases. Nature. 2012:485:114-8.

24. Wang Y, Mao Q, Liu W, Mar T, Wei T, Liu Y, et al. Localization and distribution of Wheat dwarf virus in its vector leafhopper, Psammotettix alienus. Phytopathology. 2014;104:897-904.

25. Digonnet $C$, Martinez $Y$, Denance $N$, Chasseray M, Dabos $P$, Ranocha $P$, et al Deciphering the route of Ralstonia solanacearum colonization in Arabidopsis thaliana roots during a compatible interaction: focus at the plant cell wall. Planta. 2012;236:1419-31.

26. Kim ST, Kim SG, Agrawal GK, Kikuchi S, Rakwal R. Rice proteomics: a model system for crop improvement and food security. Proteomics. 2014;14:593-610.

27. Agrawal GK, Rakwal R. Rice proteomics: A move toward expanded proteome coverage to comparative and functional proteomics uncovers the mysteries of rice and plant biology. Proteomics. 2011;11:1630-49.

28. Marsh E, Alvarez S, Hicks LM, Barbazuk WB, Qiu W, Kovacs L, et al. Changes in protein abundance during powdery mildew infection of leaf tissues of Cabernet Sauvignon grapevine (Vitis vinifera L.). Proteomics. 2010:10:2057-64.

29. Ross PL, Huang YLN, Marchese JN, Williamson B, Parker K, Hattan S, et al. Multiplexed protein quantitation in Saccharomyces cerevisiae using aminereactive isobaric tagging reagents. Mol Cell Proteomics. 2004;3:1154-69.

30. Karp NA, Huber W, Sadowski PG, Charles PD, Hester SV, Lilley KS. Addressing accuracy and precision issues in iTRAQ quantitation. Mol Cell Proteomics. 2010;9:1885-97.

31. Gross W, Lenze D, Nowitzki U, Weiske J, Schnarrenberger C. Characterization, cloning, and evolutionary history of the chloroplast and cytosolic class I aldolases of the red alga Galdieria sulphuraria. Gene. 1999;230:7-14.

32. Lai MM. Cellular factors in the transcription and replication of viral RNA genomes: a parallel to DNA-dependent RNA transcription. Virology. 1998;244:1-12.

33. Hara MR, Agrawal N, Kim SF, Cascio MB, Fujimuro M, Ozeki Y, et al. Snitrosylated GAPDH initiates apoptotic cell death by nuclear translocation following Siah1 binding. Nat Cell Biol. 2005;7:665-74.

34. Wang RY-L, Nagy PD. Tomato bushy stunt virus co-opts the RNA-binding function of a host metabolic enzyme for viral genomic RNA synthesis. Cell Host Microbe. 2008;3:178-87.

35. Prasanth KR, Huang Y-W, Liou M-R, Wang RY-L, Hu C-C, Tsai C-H, et al. Glyceraldehyde 3-phosphate dehydrogenase negatively regulates the 
replication of Bamboo mosaic virus and its associated satellite RNA. J Virol. 2011;85:8829-40

36. Zaffagnini M, Fermani S, Costa A, Lemaire SD, Trost P. Plant cytoplasmic GAPDH: redox post-translational modifications and moonlighting properties. Front Plant Sci. 2013;4:450.

37. Kaido M, Abe K, Mine A, Hyodo K, Taniguchi T, Taniguchi H, et al. GAPDH-a recruits a plant virus movement protein to cortical virus replication complexes to facilitate viral cell-to-cell movement. PLoS Pathog. 2014;10:e1004505.

38. Han S, Wang Y, Zheng X, Jia Q, Zhao J, Bai F, et al. Cytoplastic glyceraldehyde-3phosphate dehydrogenases interact with ATG3 to negatively regulate autophagy and immunity in Nicotiana benthamiana. Plant Cell. 2015;27:1316-31.

39. Aranda MA, Escaler M, Wang DW, Maule AJ. Induction of HSP70 and polyubiquitin expression associated with plant virus replication. Proc Natl Acad Sci U S A. 1996;93:15289-93.

40. Whitham SA, Yang CL, Goodin MM. Global impact: Elucidating plant responses to viral infection. Mol Plant Microbe In. 2006;19:1207-15.

41. Wang S, Blumwald E. Stress-induced chloroplast degradation in Arabidopsis is regulated via a process independent of autophagy and senescenceassociated vacuoles. Plant Cell. 2014;26:4875-88.

42. Schelbert S, Aubry S, Burla B, Agne B, Kessler F, Krupinska K, et al. Pheophytin Pheophorbide Hydrolase (Pheophytinase) is involved in chlorophyll breakdown during leaf senescence in Arabidopsis. Plant Cell. 2009:21:767-85.

43. Moulin M, McCormac AC, Terry MJ, Smith AG. Tetrapyrrole profiling in Arabidopsis seedlings reveals that retrograde plastid nuclear signaling is not due to Mg-protoporphyrin IX accumulation. Proc Natl Acad Sci U S A. 2008;105:15178-83.

44. Lundqvist J, Elmlund $\mathrm{H}$, Wulff RP, Berglund L, Elmlund D, Emanuelsson C, et al. ATP-induced conformational dynamics in the AAA+ motor unit of magnesium chelatase. Structure. 2010;18:354-65.

45. Sawicki A, Willows RD. Kinetic analyses of the magnesium chelatase provide insights into the mechanism, structure, and formation of the complex. J Biol Chem. 2008;283:31294-302.

46. Kuwata S, Masuta C, Takanami Y. Reciprocal phenotype alterations between two satellite RNAs of cucumber mosaic virus. J Gen Virol. 1991;72:2385-9

47. Masuta C, Takanami Y. Determination of sequence and structural requirements for pathogenicity of a cucumber mosaic virus satellite RNA (Y-satRNA). Plant Cell. 1989;1:1165-73.

48. Vierstra RD. The ubiquitin-26S proteasome system at the nexus of plant biology. Nat Rev Mol Cell Bio. 2009;10:385-97.

49. Smalle J, Vierstra RD. The ubiquitin 265 proteasome proteolytic pathway. Annu Rev Plant Biol. 2004:55:555-90.

50. Dudler R. Manipulation of host proteasomes as a virulence mechanism of plant pathogens. Annu Rev Phytopathol. 2013;51:521-42.

51. Dielen AS, Badaoui S, Candresse T, German-Retana S. The ubiquitin/26S proteasome system in plant-pathogen interactions: a never-ending hideand-seek game. Mol Plant Pathol. 2010;11:293-308.

52. Vierstra RD. Proteolysis in plants: mechanisms and functions. Plant Mol Biol. 1996:32:275-302.

53. van Loon LC, Rep M, Pieterse CMJ. Significance of inducible defense-related proteins in infected plants. Annu Rev Phytopathol. 2006;44:135-62.

54. Marković-Housley Z, Degano M, Lamba D, von Roepenack-Lahaye E, Clemens S, Susani M, et al. Crystal structure of a hypoallergenic isoform of the major birch pollen allergen Bet $\mathrm{v} 1$ and its likely biological function as a plant steroid carrier. J Mol Biol. 2003;325:123-33.

55. Liu JJ, Ekramoddoullah AKM. The family 10 of plant pathogenesis-related proteins: Their structure, regulation, and function in response to biotic and abiotic stresses. Physiol Mol Plant P. 2006;68:3-13.

56. Park CJ, Kim KJ, Shin R, Park JM, Shin YC, Paek KH. Pathogenesis-related protein 10 isolated from hot pepper functions as a ribonuclease in an antiviral pathway. Plant J. 2004:37:186-98.

57. Casado-Vela J, Selles S, Martinez RB. Proteomic analysis of tobacco mosaic virus-infected tomato (Lycopersicon esculentum M.) fruits and detection of viral coat protein. Proteomics. 2006;6:S196-206.

58. Wu L, Han Z, Wang S, Wang X, Sun A, Zu X, et al. Comparative proteomic analysis of the plant-virus interaction in resistant and susceptible ecotypes of maize infected with sugarcane mosaic virus. J Proteomics. 2013;89:124-40.

59. Ventelon-Debout M, Delalande F, Brizard JP, Diemer H, Van Dorsselaer A, Brugidou C. Proteome analysis of cultivar-specific deregulations of Oryza sativa indica and O. sativa japonica cellular suspensions undergoing Rice yellow mottle virus infection. Proteomics. 2004;4:216-25.
60. Zhang $X$, Wang $X$, Zhou G. A one-step real time RT-PCR assay for quantifying rice stripe virus in rice and in the small brown planthopper (Laodelphax striatellus Fallen). J Virol Methods. 2008;151:181-7.

61. Huang DW, Sherman BT, Lempicki RA. Systematic and integrative analysis of large gene lists using DAVID bioinformatics resources. Nat Protoc. 2009;4:44-57.

62. Kanehisa M, Goto S, Sato Y, Kawashima M, Furumichi M, Tanabe M. Data, information, knowledge and principle: back to metabolism in KEGG. Nucleic Acids Res. 2014;42:D199-205.

63. Franceschini A, Szklarczyk D, Frankild S, Kuhn M, Simonovic M, Roth A, et al. STRING v9.1: protein-protein interaction networks, with increased coverage and integration. Nucleic Acids Res. 2013;41:D808-15.

64. Liu B, Chen Z, Song X, Liu C, Cui X, Zhao X, et al. Oryza sativa Dicer-like4 reveals a key role for small interfering RNA silencing in plant development. Plant Cell. 2007;19:2705-18.

65. Zhang P, Mar TT, Liu WW, Li L, Wang XF. Simultaneous detection and differentiation of Rice black streaked dwarf virus (RBSDV) and Southern rice black streaked dwarf virus (SRBSDV) by duplex real time RT-PCR. Virol J. 2013;10:24.

66. Livak KJ, Schmittgen TD. Analysis of relative gene expression data using real-time quantitative PCR and the $2^{-\Delta \Delta C T}$ Method. Methods. 2001;25:402-8.

67. Russell DW, Sambrook J. Molecular cloning: a laboratory manual. Cold Spring Harbor Laboratory Press. 2001.

\section{Submit your next manuscript to BioMed Central and take full advantage of:}

- Convenient online submission

- Thorough peer review

- No space constraints or color figure charges

- Immediate publication on acceptance

- Inclusion in PubMed, CAS, Scopus and Google Scholar

- Research which is freely available for redistribution 